\title{
JAUNDICE OF INFECTIVE ORIGIN
}

\section{By BERTRAND DAWSON AND WILLIAM E. HUME}

\author{
With Plates 10-16
}

THE following account is chiefly based on a study of 178 cases of jaundice which were admitted during nine months to the 14th General Hospital (Lieut.Colonel Goodwin, D.S.O.,C.M.G.) and the 14th Stationary Hospital (Lieut.-Colonel Evans, D.S.O.), to whom our thanks are due for facilities in investigating the cases under their care.

The majority can be classified into one of the three following groups :

A. Spirochaetal jaundice.

B. Enteric jaundice.

C. 'Catarrhal' jaundice (including some indeterminate forms).

(A.) Spirochaetal jaundice. Certain Japanese authors ${ }^{1}$ have described a disease in which jaundice was a constant feature, and have proved it to be due to a spirochaete (spirochaetosis icterohaemorrhagica). They showed that the blood of those patients caused jaundice in guinea-pigs, and they also obtained spirochaetes from the blood and from the urine of the patients themselves. The disease described by the above authors had the following characteristics :

The illness was ushered in with fever $\left(103^{\circ}\right)$, malaise, conjunctival congestion, anorexia, and considerable prostration. Jaundice usually appeared about the fifth day of the disease, and the temperature fell to normal between the fourth and the sixth day, and in many cases was succeeded by a secondary rise of fever about the end of the second week. During the first week haemorrhages were common, that is, bleeding from the nose, lungs, stomach, bowel, and kidneys. Herpes was common. If the blood from these patients during the first few days of fever was injected into a guinea-pig the latter developed a feverish illness, with jaundice supervening on the eighth day. In some cases the spirochaete could be seen in films made from the human peripheral blood. Further, spirochaetes could be obtained from the urine of the patients themselves up to the fortieth day by centrifuging the urine.

We have been able to observe the disease and the pathological changes produced by the spirochaete in the guinea-pig, and reference to this will be made in a later part of this paper.

As most of our cases were studied before the Japanese work was known to us, the actual demonstration of the spirochaete is lacking in many of them.

1 The Etiology, Mode of Infection, and Specific Therapy of Weil's Disease (Spirochaetosis Icterohaemorrhagica), by Ryokichi Inada, M.D., Yutaka Ido, M.D., Rokura Hoki, M.D., Rarijiro Heniko, M.D., and Hiroshi Ito, M.D. (from the First Medical Clinic of the Imperial University in Kyusu, Fukuoka). Journ. of Exp. Med., March, 1916.

[Q J. M., Oct., 1916, and Jan., 1917.] 
Recently, however, we have obtained the spirochaete from the urine in the vast majority of patients suffering both from the severe and mild types of the disease.

The production of the disease in a guinea-pig by inoculation with a patient's blood can only be effected in the first three or four days of illness, and the cases seldom reach base hospitals at this early stage. Only those cases will be described in which the spirochaetes have been found, or which present a clinical or pathological picture so characteristic as to leave no reasonable doubt that they are identical with the disease described by the Japanese workers.

For convenience of description the cases will be divided into two groups: (1) severe, (2) mild. This is an arbitrary division in which the dividing line is ill-defined, as the two groups merge one into the other, and perhaps the largest number of cases adjoin the line of demarcation.

\section{Group I. Severe Cases.}

A general description of eighteen cases in this group will now be given, and will be followed by a detailed account of four cases which were investigated either at operation or post-mortem. The chief signs and symptoms are shown in Table $I$.

The patients were serving in the trenches when they became ill, and the account of the early stage of the disease is taken either from the patients' descriptions or from notes sent from the casualty clearing hospitals.

The onset was sudden in nine and gradual in nine cases. Those who were overcome suddenly complained of shivering, sudden headache, generalized pains, and a sudden prostration; as one said, he 'fell out very weak', or in another instance 'suddenly collapsed at church parade'. A gradual onset was manifested by a general seediness, faintness, headache, anorexia, nausea, and occasional vomiting. At the time of reporting sick the temperature was usually found to be raised to $102^{\circ}$ or $103^{\circ}$, and during the first two or three days the patient complained of sickness and vomiting (nine cases), great prostration and lassitude, abdominal and muscular pains. The conjunctivae were injected, and herpes about the lips was frequently observed. Briefly, the patient was seized with an acute febrile illness, with great prostration, often associated with conjunctival injection and herpes.

The jaundice appeared from the second to the seventh day after the onset of illness, and the average day of fourteen cases was 4.4 . It appeared first in the conjunctivae and rapidly spread over the trunk and limbs.

On admission to the base hospital (the average day being $8 \cdot 8$ ) the patients were seen to be ill, and were unusually heavy and drowsy. The jaundice was marked and universal. The tongue was frequently dry and covered with a brownish-white fur: in the majority there was herpes about the lips, which frequently became impetiginous.

The other features of the cases are set out under the following headings and can be seen in greater detail in Table I.

Gastro-intestinal. A dirty tongue and anorexia were common to all; 
constipation was marked, and had usually to be relieved by enemata. The stools so obtained consisted of small scybalous masses, which on being broken were clay-coloured (four) or a ligbt brownish-yellow (nine). In eleven cases there was considerable abdominal tenderness. The whole of the upper abdomen was tender, and it was thought that the point of maximum tenderness was placed just above and to the left of the umbilicus. The liver was tender in proportion to its enlargement. Though vomiting was common at the onset of the illness, it usually ceased before admission, except in the case of the patient from whom a round worm was obtained by gastric lavage.

Haemorrhages. Out of the eighteen cases included in this group fourteen had haemorrhages. Haematemesis occurred in four and haemoptysis in six. Epistaxis was considerable in four cases and slight in two. Melaena was observed in three instances, and in three purpura was marked. In one case there were epistaxis, haemoptysis, and melaena.

The Skin. Besides herpes and jaundice the noteworthy features in the skin were a curious purplish discoloration which appeared on the abdomen, loins, and lower part of the chest in those cases which were most deeply jaundiced. Little complaint was usually made of pruritus.

The Liver. In sixteen out of eighteen cases the liver was definitely enlarged to the extent of about three fingers' breadth, and the edge could usually be felt. It was frequently tender.

The Spleen was palpalle in two cases at the time they came under our observation, though in a third the edge was said to have been palpable during the patient's stay in another hospital. From observation at operation and the condition of the organ at post-mortem examination it seems certain that the spleen is not usually enlarged sufficiently to be palpable in this disease.

Lymphatic Glands were sometimes shotty.

Urinary System. The most obvious feature of the urine was the large quantity of bile, which gave the urine in most instances the colour of porter. The bile gradually disappeared in the more serious eases in four to five weeks. Albumin was present in fifteen out of the eighteen cases, for the most part coming down as a distinct cloud on boiling the urine, though at times there was as much as an eighth of a boiled test-tube. The urine was usually free from albumin in three weeks in the patients who recovered. Casts, hyaline and granular, were found in nine of the cases. At times free red blood cells and epithelial cells were seen. The nitro-prusside test disclosed no acetone in the urine of those patients who became comatose prior to death.

Muscular Pains. In twelve cases pains in the muscles of the back, thighs, and legs were considerable.

Nervous System. Frontal headache and aching behind the eyeballs was a constant complaint and was little relieved by antipyretics. One patient complained of green vision. Convulsions preceded coma in two fatal cases.

The Circulatory System. There is nothing notewortby in an examination of the heart, except that one patient had a temporary auricular fibrillation, 
polygraphic tracings of which were recorded. In many instances the atropin test, as devised by Captain Marris, R.A.M.C., was applied, and $\frac{1}{33}$ gr. was administered hypodermically. In this spirochaetal group the heart escaped on each occasion to the extent of $25-50$ beats, contrasting markedly with the lack of escape which the heart exhibited in those cases of jaundice which were proved to belong to the enteric group. The pulse-rate is somewhat slow in proportion to the range of temperature.

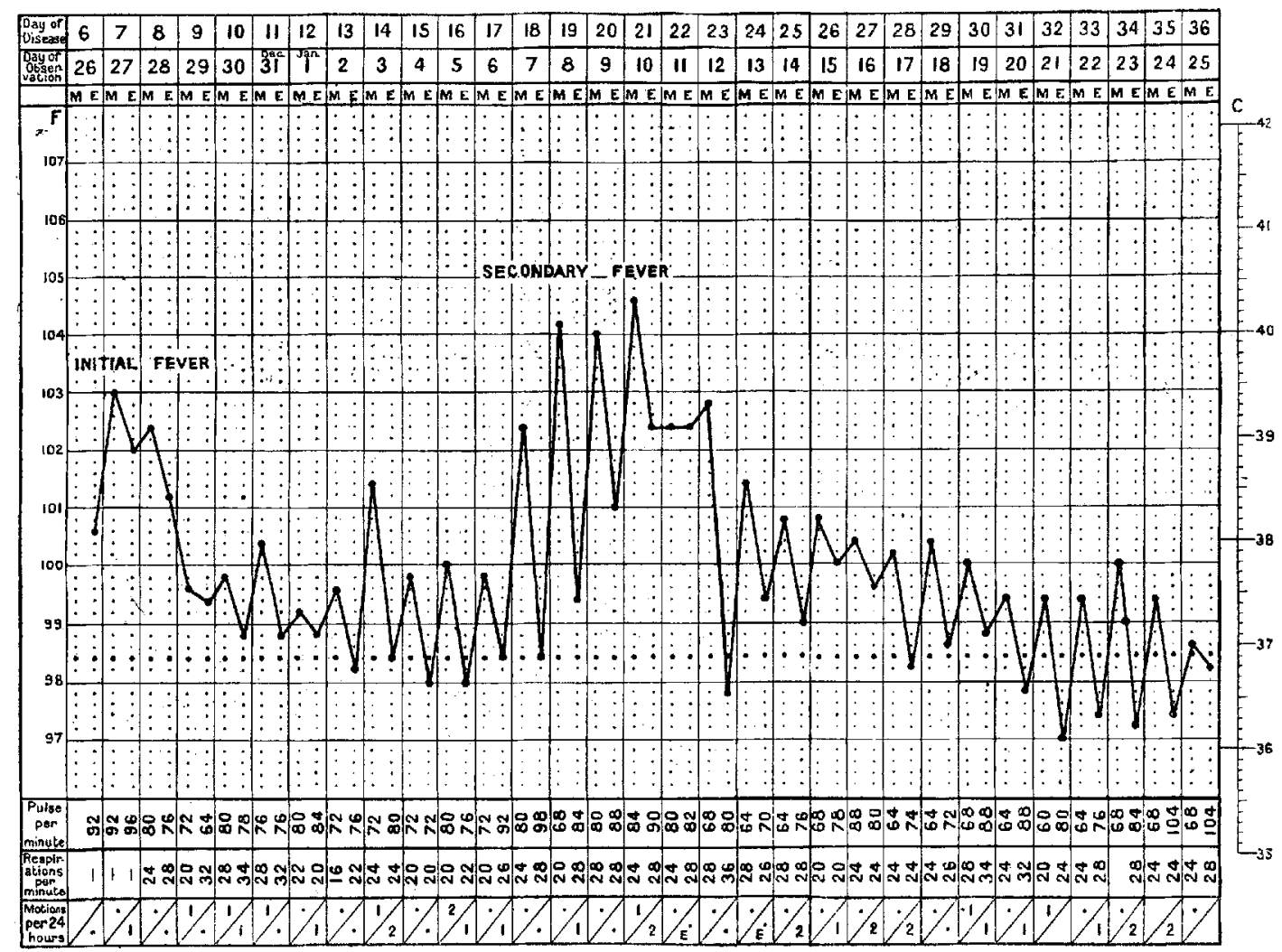

Chart I.

The blood pressure was norma], and again contrasted with the lower pressures met with in the enteric group. Examinations of the peripheral blood were always made. The more serious cases became slightly anacmic, and on one occasion a red count as low as 2,160,000 was found. The white counts for the most part showed a leucocytosis, and in thirteen the white cells were over 10,000 per c.mm. of blood. Differential counts showed that there was a relative increase of the polymorphonuclear leucocytes. The fragility of the red cells was tested on two occasions and was found to be normal. In no instance did the blood films show evidence of such reaction on the part of the bone marrow as would have been expected after blood destruction-that is, no marked variations in size or shape, no polychromasia, and no nucleated red cells were present.

The Fever. The initial rise of temperature has been noted in the description of the onset of the fever, rising usually to $103^{\circ}$. After seven to eight days the 
temperature reached normal and usually remained normal for four to five days. In six cases there was a definite period of secondary fever, as shown in Chart $I$. In the remaining eight cases the temperature rose a little about the fourteenth day and remained at a higher range for some days-a smaller degree of secondary fever (Chart II). Four patients were sent to England as soon as the initial fever waned.

Course of the Disease. At the end of seventeen to twenty days the patients usually showed signs of commencing convalescence, and the average stay in hospital was seventeen to twenty-one days. At the end of three weeks the temperature would usually swing between $97^{\circ}$ and $99^{\circ}$ p.m., and this mild

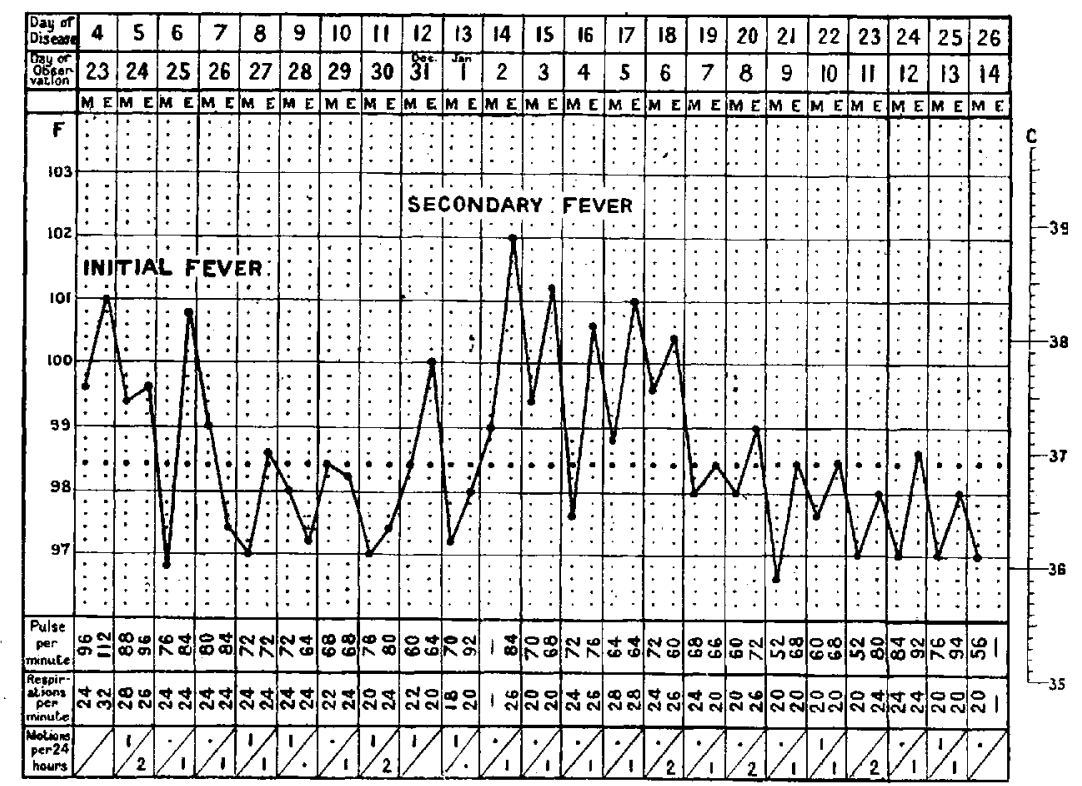

Chart I1.

degree of fever continued up to the time of the patient's departure for England, even though be was going about and otherwise seemed perfectly well.

\section{Special Cases.}

Table I, No. 1. Aged 38. Began to retch and vomit on November 10, 1915 ; on November 12 he noticed that 'his water was like blood', and on November 13, feeling drowsy and ill, be reported sick.

On admission on November 15 he looked ill and drowsy. The bowels had not been opened for seven days, which gave rise to considerable abdominal distension and discomfort. There was a thick brown fur on the tongue and marked universal jaundice. The abdominal distension was relieved by an enema, but tenderness in the epigastrium persisted. The liver was palpable and tender, its lower edge extending for two fingers' breadth below the costal margin. No .enlargement of the spleen could be detected. 
The urine was loaded with bile and a large cloud of albumin appeared on boiling. There were fairly numerous hyaline and granular casts.

The temperature on admission varied between $100^{\circ}$ and $102^{\circ}$ and fell to $98.6^{\circ}$ on the twelfth day of illness; on the thirteenth day it began to rise again, reaching $103 \cdot 2^{\circ}$ on the sixteenth day. This secondary rise lasted till the twentyseventh day. The pulse varied between 72 and 104 and was of normal volume and tension. The stools were constipated, light brown in colour, and obviously contained some bile. During the first week in hospital the patient was toxic and drowsy.

An examination of the blood showed 5,200,000 red cells per c.mm. and 13,000 white cells. The differential count of the latter showed a normal propor-

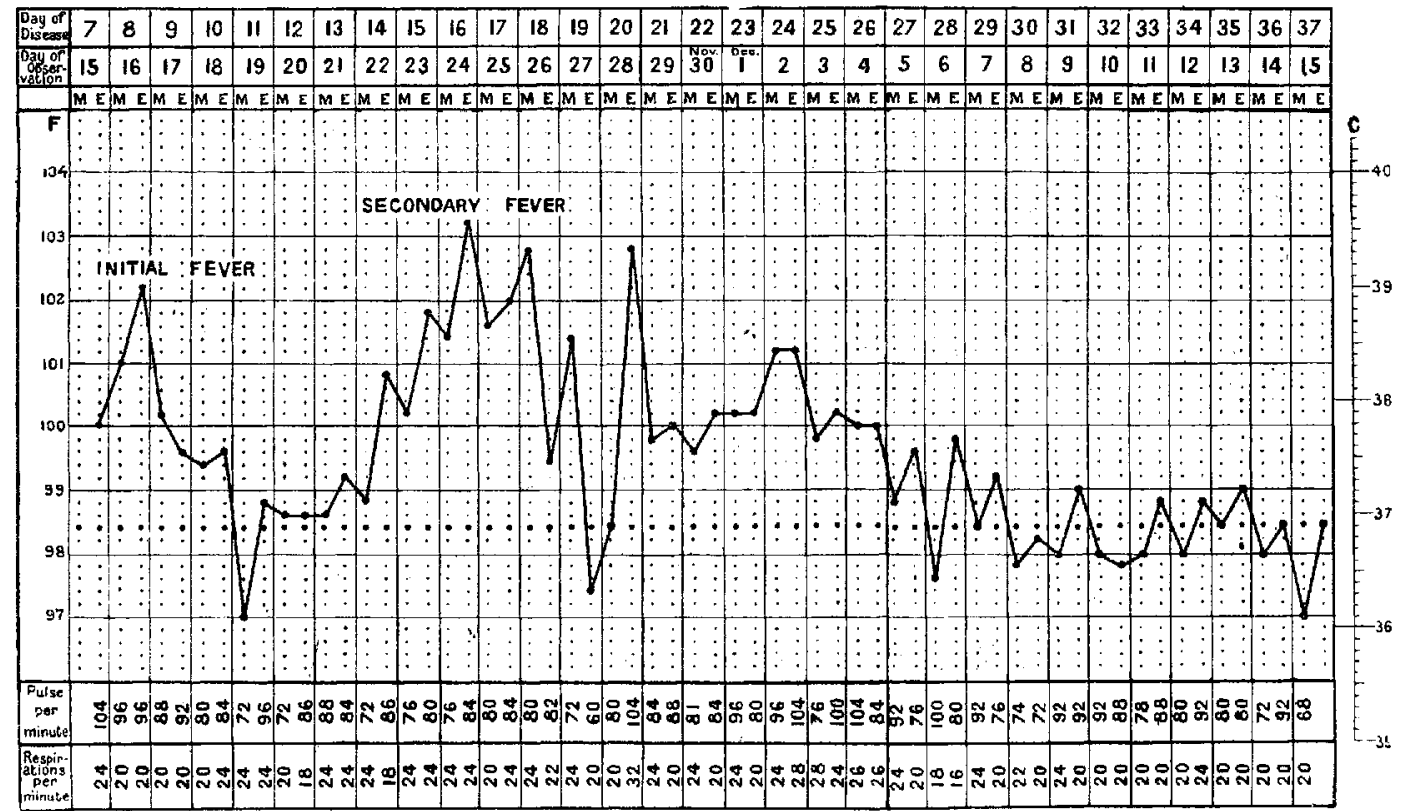

ChakT III.

tion of cells: Polymorphs, 63 ; ]ymphocytes, 33 ; coarsely granular eosinophils, 4 per cent.

On November 24 the patient complained of faintness and a feeling of absolute weakness. On November 25 the temperature was $101.8^{\circ}$; pulse 80 and respirations 20. He complained of pain in the feet extending up the shins to the knees. The shins were tender, as also were the calves of the legs.

On November 27 it was decided to open and drain the gall-bladder, and Colonel Andrew Fullerton, C.M.G., A.M.S., performed the operation. The abdomen was opened along the right border of the right rectus and the gallbladder, which was small and pale, was drained. During the operation the liver was noted to be plum-coloured and 'friable', and a puncture was made into it for bacteriological purposes. There was no shock after the operation, the gallbladder drained well and the patient improved steadily, and on November 30 
the jaundice was considerably less. The tube was removed from the gallbladder on December 8, and on December 29 the patient left for England. He wrote later and stated that he was very well (January 1, 1916).

Bacteriological Examination of Fluids removed at Operation.

1. From the liver was grown a coliform organism which was not agglutinated by the patient's blood serum.

2. From the gall-bladder a few colonies of staphylococci.

Table I, No. 4 was taken suddenly ill at church parade and vomited on November 14. Muscular power left him and he was unable to stand, and from November 14 to November 28 vomiting was frequent and he complained of epigastric pain. Jaundice appeared on the fifth day of the disease.

$\mathrm{H}_{e}$ was admitted to hospital on November 28, and was then intensely jaundiced and in a drowsy state. He complained of spasms of pain across the epigastrium. Constipation was very obstinate and required the use of enemata. The stools were grey-white in colour. There was marked tenderness in the epigastrium, and the edge of the liver could be felt two fingers' breadth below the costal margin. The spleen was not palpable. Examination of the urine disclosed a large quantity of bile, a distinct cloud of albumin on boiling, and very numerous hyaline and granular casts.

On November 30 the patient was drowsy and intensely jaundiced.

On Decernber 1 the gall-bladder was drained by Colonel Fullerton, A.M.S., and at the same time stabs were made into the liver and spleen for bacteriological investigation. Cultures from these showed:

1. From the liver. A coliform organism which formed acid and gas with all the sugars.

2. From the spleen. A coliform organism which formed acid and gas in glucose only.

The patient died at 2.45 on December 1 .

Table I, No. 3 reported sick on December 12, complaining of pains in the legs and vomiting. On that day he vomited half a pint of clotted blood. He remained in his billet for five days and was then sent to hospital. At this time he was very ill and drowsy. He became jaundiced on December 19.

On December 22 the conjunctivae, skin, and mucous membranes showed an extreme degree of jaundice. The abdomen was distended, though not rigid, and there was tenderness in the right hypochondrium. The tongue was coated; there was no oral sepsis. There was a slight bronchitis and a small quantity of blood-stained sputum. The urine was bile-stained, albumin was present, but no renal casts were found. The stools were semi-solid and claycoloured.

On December 26 the abdominal distension was very marked and the thoracic viscera seemed to be displaced upwards, the lower part of the left chest moving poorly. The patient was breathless and rather drowsy.

On December 31 the patient was less drowsy and the jaundice less marked, and next day the temperature was normal. The pulse-rate varied between 88 and 
96. On January 3 the drowsiness had again increased, and henceforward persisted.

On January 7 there was a general convulsion; the face twitched and there were clonic spasms of the arms and legs. After this convulsion the clinical picture resembled that of diabetic coma; the respirations were increased in range, the temperature was $96.4^{\circ}$, and the pulse 140 ; the patient could be roused, but quickly relapsed into stupor. Gradually this stupor deepened, passed into coma, and death occurred on January 9. During the last week of life there was a rapid and progressive loss of flesh, and the jaundice continued to diminish.

Table I, No. $2^{2}$ was taken ill with a sudden chill and shivering on December 16. He had to take to bed, and complained of headache, nausea, and pains in both thighs. He frequently felt chilly and had pain in the epigastrium. On December 21 he became jaundiced. On this day there were no abnormal physical signs to be detected in any of the systems except some epigastric tenderness. Vomiting ensued and nothing could be retained in the stomach, and on December 24, while attempting gastric lavage, the patient vomited and a round worm was voided.

During the following week the jaundice steadily deepened in intensity and the urine was deeply bile-stained. The stools were liquid and of a pale yellow colour. Nausea was marked, and there was constant vomiting of small amounts of uncoloured mucus. Daily lavage of the stomach was carried out with no relief.

Except on the first day, when the temperature was $101^{\circ}$, there was no pyrexia, and both the pulse and respiration rates fell to 60 and 16 respectively There was considerable tenderness of the upper abdomen and the muscles were slightly rigid. The liver was enlarged and the edge extended three fingers' breadth below the costal margin. The spleen was not palpable. An examination of the blood showed 34,100 white cells per c.mm., and the differential count was:

$$
\begin{aligned}
& \text { Polymorphonuclear leucocytes . . } 93 \text { per cent. } \\
& \text { Lymphocytes . . . . . } 6 \text { per cent. } \\
& \text { Large mononuclears . . . . } 1 \text { per cent. }
\end{aligned}
$$

The urine contained a large quantity of bile and one-eighth of a boiled test-tube of albumin. A culture made from the urine was sterile.

The faeces showed some blood, but no parasites, no ova, and no organisms of the enteric group.

In the forenoon of December 29 some twitching of the face and arms was noticed, and about one hour afterwards the patient had a general tonic, and later clonic convulsion. The heart sounds had become very weak, and respiration ceased an hour after the convulsion. During life blood cultures and agglutinations both proved negative to the enteric group.

${ }^{2}$ We were enabled to study this case through the kindness of our colleagues of tho Harvard Unit. 


\section{Group II. Mild Cases.}

From the foregoing descriptions the impression might be gathered that spirochaetosis always gives this defined picture. This is not so. The majority are less severe in their manifestation, as the following case exemplifies:

Rifleman P., aged 22 years, was admitted to a field ambulance with a slight shrapnel wound of the finger. Two days later (June 16) he was suddenly seized with pains all over the body, headache, and vomiting, and his temperature was found to be $102^{\circ}$. On June 21 there were suffusion and slight icterus of the conjunctivae.

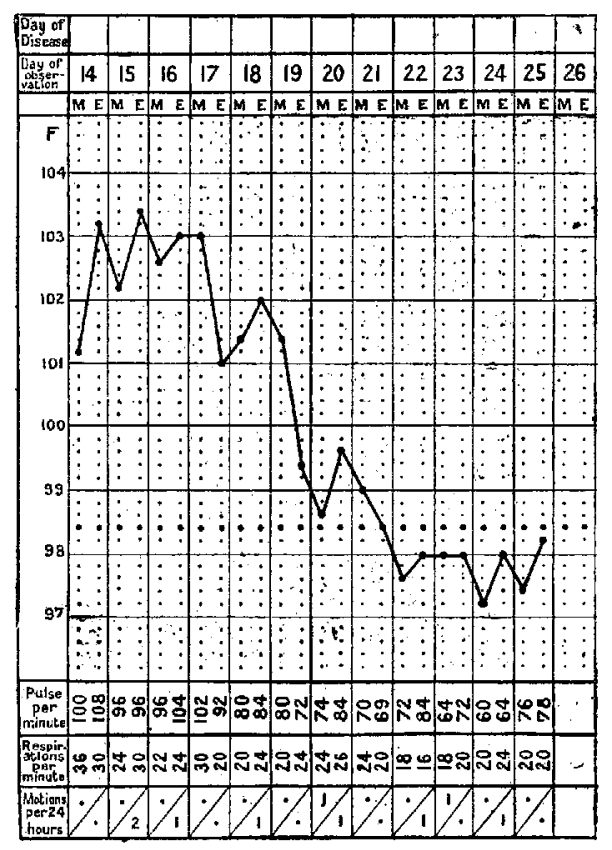

CharT IV.

On June 24 jaundice was marked and the patient was rather drowsy and felt miserable. Physical examination of the abdomen revealed slight tenderness of the liver and no enlargement of the spleen. The axillary glands were just palpable, but there was no glandular enlargement elsewhere.

On June 25 there was general moderate jaundice of the whole body and some skin irritability. The temperature was $98^{\circ}$ and the pulse rate 64 . The patient was alert and expressed himself as feeling much improved. No enlargement of the liver or spleen could be detected. The white blood cells numbered 8,500 per c.mm. and the percentage of white cells was :

Polymorphonuclear leucocytes . . . . 72 per cent.

Lymphocytes . . . . . . $\quad$. 20 per cent.

Large mononuclears . . . . . . 8 per cent. 
On the same day $\frac{1}{30}$ grain atropin sulphate was given hypodermically and the heart rate increased from 60 to 90 beats per minute.

Spirochaetes were found in the urine on June 27.

By June 28 the jaundice was fading rapidly, the temperature and pulse rate had become normal, and the patient was convalescent.

A complete analysis has been made of fifty-eight mild cases. It will only be necessary to draw attention to the incidence of the main features and characteristics of this group. This can be most readily shown by the following table:

Synopsis of Fifty-eight Mild Cases.

1. Onset. Gradual . . . . . . . . 42

2. Initial fever Sudden . . . . . . . . . . 16

(Average length of fever six to eight days.)

3. Conjunctival suff usion and photophobia . . . 50

4. Jaundice. Well marked . . . . . . . 51

5. Herpes labialis . . . . . . . . . . 30 (approx.)

6. Haemorrhage . . . . . . . . Very few.

(There is sometimes sputum tinged with blood early in the case. Unless this is specifically inquired for it would not be mentioned; hence, haemorrhage may have been commoner than this table indicates.)

7. Abdominal tenderness . . . . . . 40

8. Liver definitely enlarged in . . . . . . . 20

9. Spleen palpably enlarged in . . . . . . 1

10. Pains in the back and limbs . . . . . . 36

11. Urine. Bile . . . . . . . . . 58

Albumin . . . . . . . . 33

Casts . . . . . . . . 10

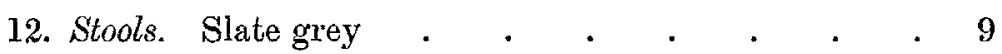

(All stools were not examined.)

13. Red blood cell count (average) . . . . . $4 \frac{1}{2}$ millions

14. Haemoglobin, average percentage . . . 90 per cent.

15. White blood cell count (over 10,000) . . . . 20

16. Secondary rise of fever. Well marked . . . 13

Slight . . . . . 8

Inquiry has shown that these patients return to duty at the end of two or three months. 


\section{Pathology.}

Stomach and small intestine. Case II died after thirteen days' illness. The jaundice was intense. The liver, stomach, duodenum, and upper jejunum were removed en masse. The mucous membrane of the duodenum was very oedematous and congested; its colour was dark blue, resembling a blue plum. In the first and second portions of the duodenum small yellow patches, varying in size from pinbeads to split peas, were seen through the mucous membrane (Brunner's glands). Round the orifice of the bile-duct there was an area about the size of a florin which was slightly raised above the surrounding mucous membrane, and in the centre of this area was the ampulla swollen and congested (Plate 10). On squeezing the gall-bladder a drop of tenacious bile appeared at the biliary orifice. The above features were seen, though in lesser degree, in the stomach and first three feet of the jejunum. The rest of the intestines was of normal appearance. At the edge of the lesser omentum and about the bile-ducts were numerous enlarged and soft lymph-glands.

In this case the terminations of the bile and pancreatic ducts were not opened, but were removed with the papilla and a bit of subjacent pancreas in order that complete microscopic sections should be made. The bile-ducts above their duodenal termination were of normal appearance.

In Case IV the illness lasted seventeen days, and the post-mortem was performed within four hours of death. The jaundice was intense. In this case the mucous membrane presented the same swollen plum-coloured appearance, but the papilla was intensely injected, its red colour contrasting with the blue of the surrounding mucous membrane. This condition of the mucous membrane, though most marked in the duodenum, extended to the pyloric half of the stomach and the upper four feet of the jejunum. The rest of the intestine was normal in appearance.

In this case the bile-duct was opened in the portal fissure and a probe passed into the duodenum. The duct was opened along the probe. An incision was made into the pancreas and the pancreatic duct laid open from that point to its termination in the ampulla of Vater. To the naked eye both the biliary and pancreatic ducts presented quite natural appearances. They were neither enlarged nor discoloured, and they presented a striking contrast to the ampulla and duodenal mucous membrane. Plate 11 faithfully reproduces the appearances, which suggested that the infection had localized in the duodenum, stomach, and upper jejunum, and that the jaundice was the result of an obstructed papilla. It may be that the duodenal congestion in these cases was exceptionally severe, but if so it the better makes manifest the process. ${ }^{3}$

In Case III the illnoss had lasted longer, viz. twenty-eight days, and the post-mortem was made within four hours of death. Jaundice was present, but was moderate in degree. Here the marked appearances noted in the duodenum of the foregoing cases were absent, except that the papilla was obvious and slightly

s A similar case is described in the appendix. 
oedematous. The common bile and cystic ducts showed no sigus of inflammation. There were large glands in the lesser omentum. Death in this case occurred at a later stage of the illness, and it may be that the inflammation of the duodenum had waned.

The microscopic appearances of the duodenum were negative, nor was there any cellular infiltration of the mucous membrane of the ampulla, the congestive swelling of which one would not expect to be shown in the sections. The minute structure of the ampulla is, however, of interest, and Professor Keith, to whom these sections (Plate 14, A and B) were shown, wrote the following note:

'The sections of the ampulla show an anatomical feature of the normal bowel which deserves attention. It is well known that the mucous membrane lining the ampulla is thrown into numerous folds, but I do not remember attention having been drawn to the numerous crypts and recesses lying at the bottom of these folds. Clearly these crypts could afford shelter for the growth and retention of infective micro-organisms. The crypts are excellently delineated by Mr. Ford.'

It is of interest to mention here that in an account of six fatal cases of Weil's disease, recorded by Beitzke (Berlin. K.W., 1916, p. 188) and Herxheimer (Berlin. K.W., 1916, p. 494), no mention is made of a duodenal lesion, except in one case in which it is stated that the mucosa was grey to red brown, the latter colour being especially marked on the summits of the folds.

The Liver. In Case II it was not enlarged, and was firm; on section it had a greenish tinge, but to the naked eye showed no other change.

In Case IV the liver extended two fingers' breadth below the costal margin and was of a bluish-grey colour. Its cut surface showed dark areas surrounded by pale rings, suggestive of cloudy swelling, but the organ was firm in texture. The intrahepatic bile-ducts appeared somewhat prominent and dilated.

In Case III the liver was enlarged to the same extent as the last case, the texture was firm, and the cut section was of a greenish hue. The lobules were, as in the other two cases, easily distinguished.

In all these cases the gall-bladder was normal in appearance and size, but the bile was unduly thick and tenacious.

In Cases II, III, and IV the liver cells appeared practically normal, and, apart from evidence of biliary stasis, the only abnormal feature was the presence of collections of cells in the portal areas, such as occur in many diseases. ${ }^{4}$ In Cases II and III these cells were mainly polymorphs, whereas in Case IV they were mostly small mononuclears, and were less numerous. Staining with Sudan III showed that fat was practically absent from the liver of Case II. The epithelial lining of the small bile-ducts was intact (Plate 13).

In contrast to the foregoing is the following description of the minute structure of the livers from two cases of spirochaetosis, for the opportunity of examining one of which we are indebted to Captain Adrian Stokes. ${ }^{5}$

\footnotetext{
${ }^{4}$ In this section on minute anatomy we have had much valuable help from Dr. C. H. Browning.

a Since this article was written an instructive paper by Capt. Stokes and Capt. Ryle has been published (Brit. Med. Journ., Sept. 13, 1916).
} 
Here (Plate 16, 8 ) the liver cells were dissociated, and many were markedly enlarged and contained well-stained nuclei. Collections of such hypertrophied cells with clear pale protoplasm appeared especially just beneath the capsule. Many liver cells contained two nuclei, and mitoses were numerous. Staining with Sudan III showed a very little fat, in the form of fine droplets, which were partly within the endothelium (Kupffer's cells).

The sum of these changes suggests the effect of damage which has been insufficient to cause extensive necrosis, but has acted as a stimulus to cell growth. In addition, the portal areas show collections of small mononuclear cells and polymorphs, and towards the centres of the lobules both intra- and extracellular granules and masses of pigment were found. These microscopic changes resemble those described by Beitzke and Herxheimer. Spirochactes could not be demonstrated in any of the livers by Levaditi's method.

The Spleen in all three cases was of normal size and consistence, which harmonizes with our clinical observations that enlargement of the spleen is uncommon.

Lymph-glands. The abdominal lymph-glands from Cases II and IV showed a marked accumulation of endothelial cells in the lymph paths, and also numerous polymorphs; many of the former were acting as phagocytes.

Kidneys. Microscopically the kidney in Case IV showed merely the appearances which are ascribed to cloudy swelling. In Cases II and III there were, in addition, scattered areas of cellular infiltration in the cortex, between the tubules and round the glomeruli. In Case II there were haemorrhages into the cortical tubules, and in the latter blood was found in many of the Bowman's capsules. Hyaline casts were seen in all cases. Staining with Sudan III in Case II shows practically no fat in the secreting tubules. Spirochaetes could not be demonstrated by the silver method in any of the specimens.

The Pancreas in all three instances showed no morbid change either to the naked eye or microscopically, and its ducts were normal. This is of interest in view of the relationship which sometimes exists between pancreatitis and bile stasis.

Lungs. In Case II there were numerous subpleural haemorrhages which extended for an inch into the lung tissue beneath, and similar, though smaller, haemorrhages within the right lung. There was no bronchitis. Sections showed extensive collections of polymorphs in and around the areas of not quite recent alveolar haemorrhage, but organisms were not found.

In Case IV there were haemorrhagic areas, $\frac{1}{4}$ to $\frac{1}{3}$ of an inch across, throughout the lower lobes of the lungs.

In Case III there were patches of bronchopnenmonia at the bases of each lung, the cellular elements of the exudate being mainly polymorphs, among which scanty cocci in tetrads were seen.

In Cases II and IV there were numerous small subserous haemorrhages over the heart. In Case IV there was a large subendothelial haemorrhage seen inside the left ventricle, involving the upper portion of the septum and extending into the papillary muscle. In Case II the brain showed no structural change. 
The brain was not bile-stained, except the choroid plexuses, which were definitely yellow.

\section{Morbid Anatomy of the Guinea-pig affected by Spirochaetosis.}

The most striking features are the jaundice and the widespread haemorrhages which may be seen beneath the skin and serous membranes, in the post-peritoneal fat, occasionally in the muscles, and in the kidneys and suprarenal capsules. The lungs present a specially characteristic appearance, being studded beneath their serous surfaces and throughout their cut sections with these patchy haemorrhages. The liver to the naked eye appears normal.

In three post-mortems the gall-bladder was of normal size; the mucous membrane of the duodenum appeared swollen, but was not congested; the biliary papilla was prominent, and it took a good deal of pressure of the gallbladder to squeeze bile into the duodenum. We have not, however, examined the duodenum of normal guinea-pigs often enough to be confident of the value of this last observation.

In sections of the guinea-pig's liver, stained by Levaditi's method, the spirochaetes are numerous and between the liver cells (Plate 15, A), in contrast to the human liver, where the spirochaetes are very few and found within the cells. Other sections show dissociation of the cells, many of which were swollen and exhibited autolytic changes. Cells showing two nuclei and also mitotic figures were here and there to be seen. There were also numerous small areas of haemorrhage scattered throughout the lobules and cellular collections-polymorphs and mononuclears - in the portal areas. Staining with Sudan III showed that the liver was practically devoid of free fat.

In the three fatal cases, II, III, and IV, the feature which first attracts attention is the absence of any definite anatomical changes in the liver. Thus, this severe and sometimes fatal infective jaundice is not necessarily associated with structural disease of the liver. It is equally clear that in some cases anatomical changes do occur as one of the results of such infection.

The cause of the jaundice in Cases II, III, and IV cannot be sought in the liver. The common bile-duct, too, is normal in size and appearance. Yet the bile stasis within the liver points either to over-production or to impeded drainage. Over-production would be the result of haemolysis, but repeated examination of blood films failed to disclose evidence of blood destruction, and in two instances in which it was tried the fragility of the blood was normal. The possibility of the jaundice being partly caused by blood destruction has not, however, been exhaustively investigated. A most likely explanation of the jaundice in many of these cases is surely to be found in the obstruction of the swollen papilla, added to increased viscosity of the bile, which was a noticeable feature in three autopsies and two operations. The swelling of the papilla is part of the general congestion of the duodenum and probably subsides when the height of the jaundice is reached, whereas the viscosity of the bile may persist for 
a longer period. Whether this thickened bile contained excess of bile pigments there was no opportunity of determining.

The congested duodenum is a local manifestation of the infection, just as the ileum is the usual place for the localization of typhoid.

The increased viscosity of the bile probably played a part in the maintenance of the jaundice, and may explain why the absence of bile pigment from the stools was less marked and prolonged than the intensity of the pigmentation of the skin suggested. The inspissated bile could maintain the back pressure in the biliary tract, but intermittently let enough bile through to partially colour the faeces. This viscosity of the bile must not, however, be looked upon as an invariable factor, for Beitzke observed the bile in his cases to be golden yellow and fluid. With calculus in the common bile duct there may be considerable depth of jaundice notwithstanding the presence of some bile in the stools.

Viewed from the immediate cause of the icterus, Cases II, III, and IV resemble 'catarrhal' jaundice in that they show obstruction of the papilla but not of the biliary ducts; on the other hand, they differ from 'catarrhal' jaundice in the severity of their symptoms. Mitamura ${ }^{6}$ describes a ease which clinically and pathologically bears the closest resemblance to Nos. II and IV. See appendix, p. 121.

Severe and even fatal jaundice can, therefore, exist sometimes associated with no definite, and at other times with very definite liver changes. The patient dies from the general infection of which jaundice is an incident and the liver changes one of the consequences. This variability in the localization of the lesion is still more marked in another spirochaetal disease, viz. syphilis.

Two of the tatal cases, Nos. II and III, seen in their later stages presented pictures of profound toxaemia such as might have characterized acute yellow atrophy or cirrhosis, yet there was no structural change in their livers. Side by side with this may be placed the observation that cases which show the clinical features of acute yellow atrophy in some instances show post mortem the marked anatomical changes of acute atrophy, and in other instances no such characteristic changes. In other words, the toxic symptoms do not primarily depend on the liver necrosis, which is rather an anatomical end product of the causal infection.

If in its course the infection had not localized in the duodenum, should we have had the same clinical picture except for the absence of jaundice? In other words, how much does the jaundice qua jaundice contribute to the toxic symptoms? Until a fatal case has occurred without jaundice it is perhaps difficult to answer this with certainty. Bile, and chiefly bilirubin, has a toxic effect on animals, and clinically we are familiar with the muscular weakness, nervous depression, slow pulse, and other symptoms associated with jaundice. On the other hand, jaundice itself is slow to produce severe or fatal toxaemia. Witness how tolerant patients are with the deep jaundice of mechanical obstruction, unless there is concurrent infection. Although the jaundice may contribute

${ }^{6}$ Zur Pathogenese des Icterus catarrhalis, Mitteit. Med. Facult. Kais. Japan. Univ. Tokio, 1915. 
to the toxaemia it cannot be its main cause. Moreover, in the fatal case, No. III, the jaundice was steadily lessening while the toxaemia deepened.

The same applies to haemorrhage. Jaundiced patients certainly have a proneness to bleed, but how far this is due to the jaundice and how far to a concurrent infection it is difficult to say. In many of these spirochaetal cases the jaundice factor is eliminated in that the haemorrhage preceded the icterus.

It occurred to us that the toxaemia of the bad cases might have been contributed to by the supervention of a microbic infection. To investigate the point we made cultures from the blood and liver punctures in the fatal cases; we punctured the liver of Cases I and IV at operation, and we bacteriologically examined the duodenal secretions. The results obtained at the autopsies we put aside, for even when the latter are done promptly the presence of coliform organisms may well be the result of impending death. The finding of eoliform organisms from the liver puncture of Cases I and IV cannot be put aside so lightly.

As regards the results of duodenal intubation, although the duodenum may contain coccal organisms in health, we are inclined to think that the presence of coliform organisms is evidence of disease, and such organisms were found in the bile obtained from the duodenum of certain of these cases. Needless to say, no inference can be drawn from these few observations, though perhaps they are worthy of mention.

Is jaundice a necessary feature of spirochatal disease? Though depth of jaundice usually goes hand in hand with severity of infection such parallelism does not always exist. It is common for a relapse of fever to occur without any interruption in the subsidence of the jaundice; in one case there was a relapse of fever after the jaundice had disappeared, but there was no return of the icterus. In one of our fatal cases the jaundice was fast disappearing during the last ten days of life when toxaemia was steadily increasing. These considerations lead one to think that jaundice, though perhaps a usual, is not a necessary manifestation of spirochaetal disease, just as typhoid may exist without intestinal ulceration.

This view received support from the fact that in the units from which the jaundice patients have come there have been simultaneous cases of fever presenting somewhat similar early symptoms but in which no icterus supervened.

Complete confirmation is established by the occurrence of cases of spirochaetosis without jaundice.

Case $A$ was in perfect health until August 25, when he began to suffer from pains in the head, back, and legs. During the next twenty-four hours he became so giddy that he was unable to go about. The next day he was sent to the dressing station, where it was found that his temperature was $102^{\circ}$. He was admitted to a base hospital on August 29. He then complained of pains in the head and back and of giddiness; there had been no vomiting and no abdominal complaint. For the first few days of his illness he had a cough; there were no haemorrhages, but there was a herpetic rash on the lips. As will be seen from the temperature chart (Chart V), the illness was short and the temperature rapidly became normal. 
On September 8 he still complained of some pains in the shins at night, but otherwise felt perfectly well.

On August 29 spirochaetes were found in the patient's blood by Lieutenant Bedson, R.A.M.C., and on September 8 spirochaetes were found also in the urine.

Case B. Sudden onset with body pains, frontal headache, photophobia, and vomiting. Temperature on the first day was $104^{\circ} \mathrm{F}$, pulse 100 , and patient was very ill. Conjunctivae were injected; herpes labialis was present, spleen was not palpable; urine showed on heating a thick cloud of albumin, but no bile. Bilious vomiting was persistent for several days.

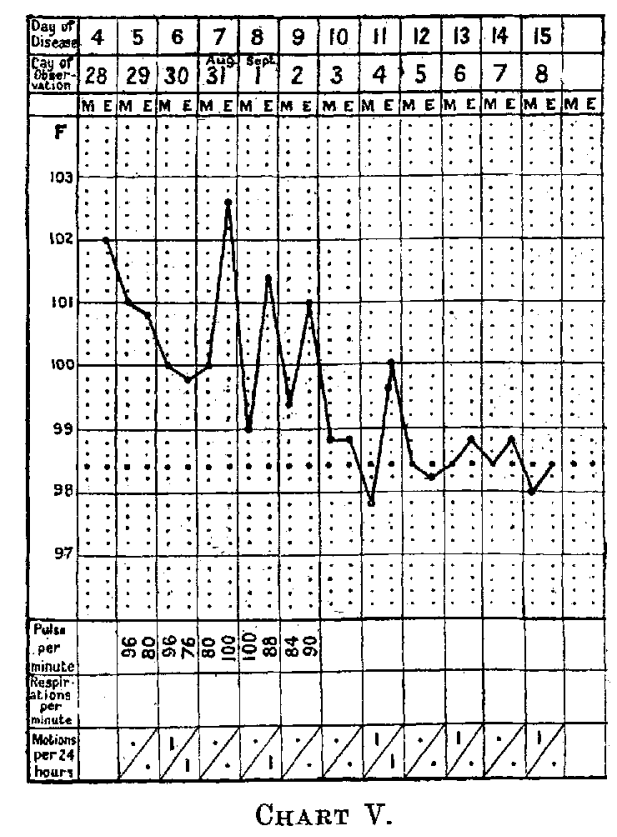

By the fourteenth day the patient appeared convalescent, but on the twentieth day there was a return of fever and pains which lasted for five days. After this, recovery was slow but continuous. Nine weeks after the onset spirochaetes were still present in the urine though health was nearly reestablished. At no time was there either jaundice or bile pigment in the urine.

On the third day of illness $2 \frac{1}{2}$ c.c. of the patient's blood were injected into the peritoneal cavity of a guinea-pig, which subsequently developed jaundice, and after death spirochaetes were to be seen in the sections of its liver.

For most of this record we are indebted to Captain H. Carson, R.A.M.C.

Case $C$ was suddenly seized with general pains and chilliness. He was admitted to a clearing hospital on the third day and was then extremely ill. Headache and backache were severe, weakness was pronounced and vomiting frequent; the temperature was $103^{\circ}$, the pulse 108 , and respiration 30 . There were neither haemorrhages nor herpes. The liver and spleen were not demonstrably enlarged. For four days the temperature remained high, but on the fifth day it fell to $99 \cdot 8^{\circ}$, and on the tenth day to normal, and remained 
so. Convalescence was rapidly established, and by the fourteenth day the patient was well enough to return to England.

The patient was never jaundiced, and though there was a suspicion of bile in the urine at the clearing hospital there was no trace of it subsequently. On the third day of illness 5 c.c. of the patient's blood were injected into a guinea-pig, which beeame ill and developed jaundice, and post mortem showed the characteristic haemorrhages in the lungs, liver, kidneys, peritoneum, and skin.

It is of interest to recall that acute yellow atrophy can occur without jaundice. Rolleston (Diseases of Liver, p. 587) relates such a case which is worth giving here. On the first day the patient suddenly felt pain and vomited a little blood, on the second and third days there was haematemesis, and on the fourth, fifth, and sixth days melaena. On the second day the liver dullness was diminished. The temperature was usually between $99^{\circ}$ and $100^{\circ} \mathrm{F}$. The patient became progressively weaker and drowsy and died on the eighteenth day. There was never any jaundice. Examination of the liver post mortem showed acute yellow atrophy. There is an interesting resemblance between this case and some of those we have recorded above.

The evidence suggests that this spirochaetosis causes either a septicaemia or a toxaemia; that it has a tendency to fall with greater force on certain, though not always the same organs; that it frequently selects the upper part of the gastro-intestinal tract and liver, and that, as a result, jaundice is a common feature; that in some cases the stomach, or it may be the ileum, is involved and the duodenum escapes, or again the brunt of the disease might fall upon the respiratory tract. In short, it would seem probable that this spirochaetosis must be added to the list of fevers independently of the presence of jaundice. It is to be admitted, however, that the explanation of the cause of the jaundice still lacks completeness. ${ }^{7}$

It is regrettable that the Japanese workers have perpetuated the name 'Weil's disease'. This title was hardly justified, for the condition had been described by the French under the more comprehensive title of 'Infectious Jaundice' prior to the publication of Weil's cases. ${ }^{8}$ Weil's disease is one of many varieties of infection characterized by jaundice and associated by some authorities with Bacillus proteus fluorescens. Nor do the clinical features of Weil's disease closely conform with those of spirochaetal jaundice. In the former the onset is sudden, the pulse rapid at the commencement, and splenic enlargement an outstanding feature; whereas in the latter the onset may be either sudden or gradual, the pulse is usually of moderate frequency (about 100 or less), and splenic enlargement is infrequent.

If the term 'Weil's disease', as has often been the case, is employed to denote any form of infectious jaundice, confusion results, and doubtless typhoid and paratyphoid fever bave often been thus disguised.

7 Later experience in the shape of further examples confirms the occurrence of spirochaetosis without jaundice, and this fact is one to be borne in mind when investigating a pyrexia of uncertain origin.

${ }^{8}$ Chauffard, Traité de Médecine, Bouchard and Brissaud. 
In this connexion it is interesting to note that under the title Typhus hépatique bénin, rechutes, guérison, Mathieu, in 1886, described symptoms suggestive rather more of spirochaetosis than of typhoid. A young man was suddenly seized with shivering, fever, headache, and repeated vomiting. On the fifth day there had appeared icterus, enlargement of the spleen, albuminuria, and purpura. By the ninth day the temperature was normal and the patient had improved. On the eighteenth day there was a relapse of fever and symptoms, lasting a week. After this recovery was uninterrupted.

(B.) Enteric jaundice. Jaundice is an uncommon feature of enteric fever. In this campaign its incidence has been rather larger than in some other collections of cases. Thus, it has been 1.38 per cent., whereas in the cases mentioned by Osler and Macrae it was 0.53 per cent. Our figures are, however, not strictly comparable, partly because paratyphoid accounts for most of our cases, and partly because improved methods of diagnosis rope in cases which would previously have passed as 'catarrhal' jaundice.

The following statement is based on twenty-six cases. In addition one case of portal pyaemia will be described. The twenty-six cases may be divided into two groups, one in which the jaundice occurred early, i. e. before the tenth day, and the other in which it occurred later in the disease. Of the total cases typhoid accounts for six, paratyphoid $A$ for four, and paratyphoid B for fourteen.

In one (Case XII, Table III), the variety of enteric ${ }^{9}$ could not be determined. In another (Case XI, Table III) paratyphoid B was obtained from the stool in the early part of the disease, and during the relapse paratyphoid $\mathrm{A}$ was obtained from the blood.

All the patients had been protected against typhoid, and of these three against paratyphoid as well. There were two deaths, one due to portal pyaemia, and the other a case of paratyphoid $B$ who had been inoculated against typhoid only six weeks previously.

The jaundice presented every grade from deep to faint pigmentation. When severe it made the patients more drowsy and toxic. Otherwise it appeared to have little effect upon the course of the illness, and if occurring later in the disease it was not necessarily associated with a return of fever or an exacerbation of symptoms.

Of the early symptoms headache is the most constant and vomiting is common. Pains in the abdomen, back, and legs, and diarrhoea may also be present. The following figures show the frequency of the early symptoms in the twenty-six cases: Headache, 19 ; vomiting, 12 ; abdominal pains, 8 ; pains in back and legs, 8 ; diarrhoea, 5 ; shivering, 2 ; extreme lassitude, 2 ; and epistaxis, 1.

In Group I (Table II), where jaundice occurs early, the onset is usually sudden, viz. eleven out of fourteen cases. This fact makes diagnosis more difficult, especially if the duration of the fever is short. This is well illustrated

'Throughout this article the term 'enteric' is used to denote the group typhoid and paratyphoid $A$ and $B$. 
by Case IV, later described in full, which might easily have been taken for 'catarrhal' jaundice.

In Group II (Table III) a gradual onset is more usual, viz. nine out of twelve cases.

In both groups the features which are associated with the typhoid fever of former days are blurred or absent. Thus abdominal distension was slight or absent; spots were noted in only four cases and the spleen palpable in only four patients. There were relapses in ten eases.

The bacteriological observations, as the tables will show, were very complete. Most of them were made at the laboratory (Captain Perry) of the 14th Stationary Hospital, and some by Lieutenant Bedson.

It will be noticed that their conclusions are ehiefly based on the aggluti. nations. In such cases as these, blood cultures could seldom be obtained early enough to be of use, and one of the results of preventive inoculation is to diminish the likelihood of finding the organisms in the stools and urine. The following cases are illustrative of jaundice occurring early in the illness (typhoid, paratyphoid $A$ and $B$ fevers) :

Typhoid fever. Case I, Table II, was seized with a sudden pain across the abdomen while 'throwing up' sandbags on March 31. This pain continued during the rest of the day and night, and the following evening he vomited. The third day he was sent to the field ambulance, where he was told that he was jaundiced.

During the first week of illness he had a continual pain in the abdomen and the bowels were constipated. The fever was not high. On the eighth day the patient was intensely jaundiced and rather drowsy; the tongue was dry and coated with a brown fur: the temperature was $98.8^{\circ}$ and the pulse-rate 70 ; the abdomen was distended and there was a feeling of resistanee in the right hypochondrium. The edge of the spleen could be felt a hand's breadth below the left costal margin and the liver edge three fingers' breadth below the ribs. The urine was loaded with bile and urates; there was a large cloud of albumin and a few bile-stained casts. The motions were constipated and of a light yellow-brown colour. The white cells of the blood numbered 4,000 per c.mm. on the eighth day and a differential count showed:

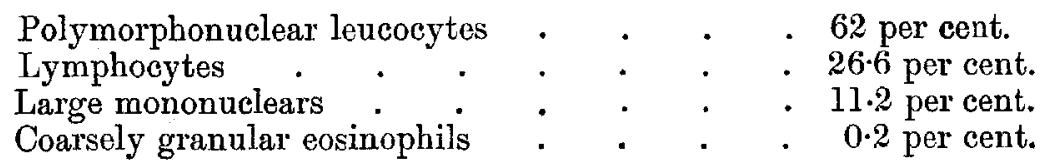

During the following five days the patient improved considerably, and by the thirteenth day the jaundice had largely faded, and on the nineteenth day had disappeared.

On the twenty-second day the white cells had risen to 5,800 per c.mm., and the differential count showed:

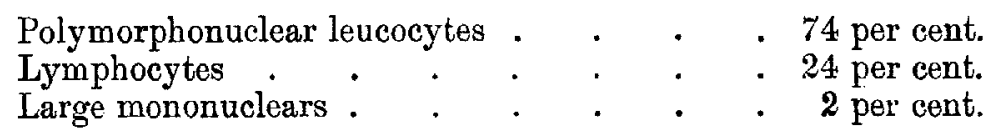

On the twenty-fourth day the spleen was still palpable though the patient was convalescent. On three occasions, on the twelfth, fourteenth, and twentyfourth days of disease, $\frac{1}{30}$ grain of atropin sulphate was administered hypo- 
dermically, and the heart-rate was increased so slightly that on this fact alone a provisional diagnosis of 'enteric group' was based.

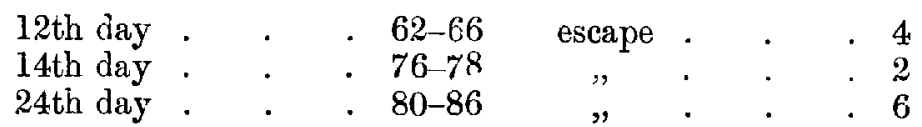

Chart VI records the experiment earried out on the twelfth day, and contrasts markedly with Chart VII, which was compiled from a case of spirochaetal jaundice. In its onset and clinical features this case was very similar to cases of spirochaetal jaundice of moderate severity. The points of distinction were(1) the considerable enlargement of the spleen; (2) the refusal of the heart to quicken after the injection of $\frac{1}{30}$ grain of atropin sulphate; (3) the bacteriological proof of infection by the Bacillus typhosus by agglutination.

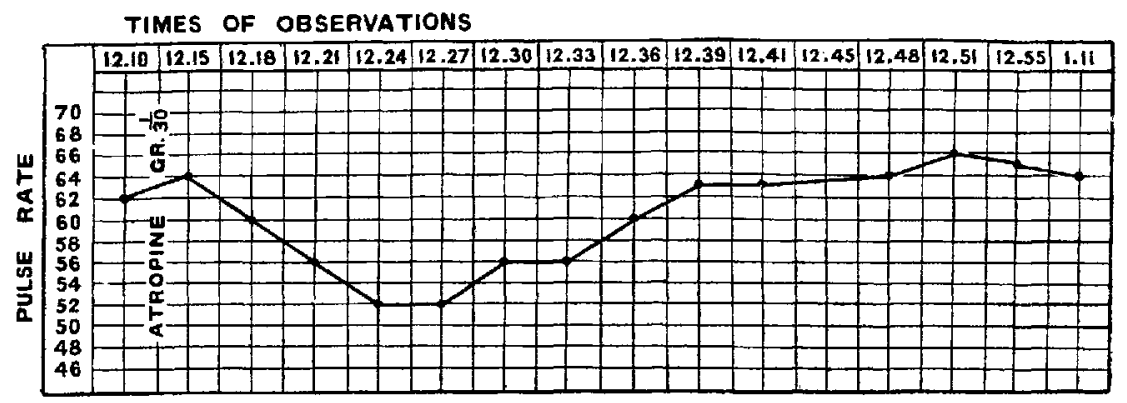

Chart VI.

Case I, Table II. Atropin experiment. Escape of heart $=62-66=4$.

TIMES OF OBSERYATIONS

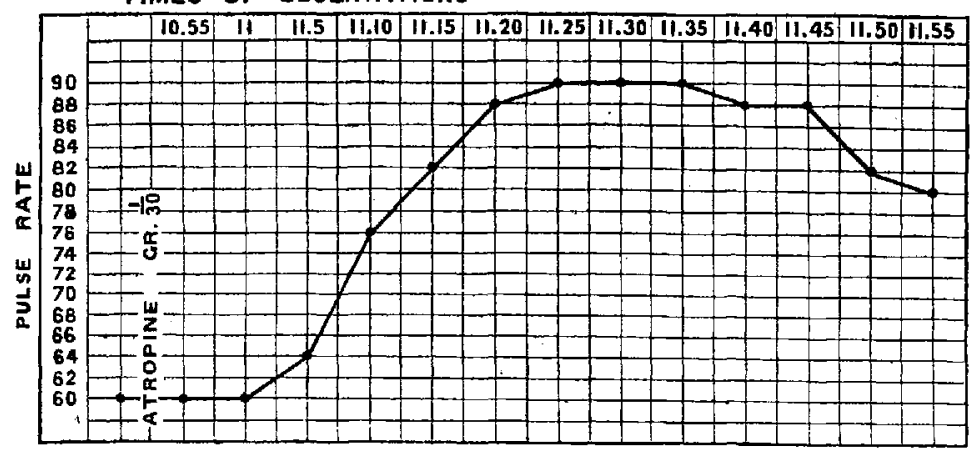

Chart VII.

Case VI, Table I. Atropin experiment. Escape of heart $=60-90=30$.

Case IV, Table II, aot. 22. ${ }^{10}$ There was a sudden onset with extreme lassitude and headache which forced him to bed within a few hours. On the second day there were pains in the head, legs, and across the abdomen, and the temperature was $103 \cdot 6^{\circ}$. On the fifth day there was repeated vomiting, with which streaks of blood appeared, and ieterus, which had shown itself on the previous day, had become definite. By the sixth day the jaundice was deep, though the temperature had fallen and the pulse-rate was 88 ; the abdomen was flat but tender in its upper half; the spleen was not enlarged, but the liver extended three fingers' breadth below the costal margin; no herpes; the glands were shotty; the patient was apathetic and drowsy. The next day the apathy continued and there was vomiting. On the eighth day the white cells were 23,800 per c.mm.,

${ }^{10}$ We are indebted to our colleagues of the sid Canadian Hospital for notes of this case. 
the red cells $4,800,000$, and the haemoglobin was 80 per cent. Films showed the red cells to be normal. On the tenth day there was still apathy; the tongue was dry in the centre and furred at the side; the spleen was enlarged to percussion, but not palpable; the urine had a specific gravity of 1011, was acid, contained bile and numerous hyaline and granular casts, a few red blood cells, but no albumin. The casts had disappeared two days later and a trace of albumin had appeared.

On the fifteenth day the patient's condition had improved; the jaundice, though still marked, was diminishing; the spleen, however, had become distinctly palpable. Blood pressure was 118 systolic and 58 diastolic. In spite of a slight rise of temperature on the sixteenth day the patient's condition steadily improved and the jaundice faded. On the tenth day, after the injection of $\frac{1}{30}$ grain of atropin, the maximum acceleration of the heart was only six beats (70 to 76) in 50 minutes. On the sixteenth day the same dose of atropin produced an escape of twenty-four beats (68 to 92) in half an hour.

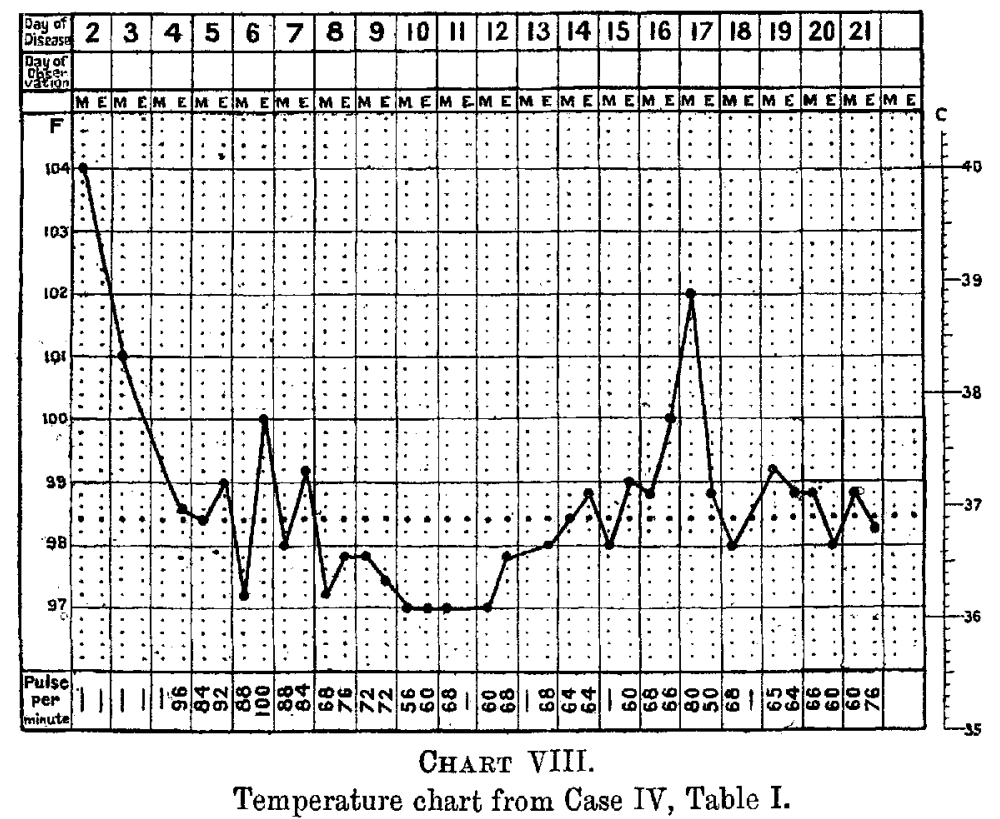

The difference in these two observations illustrates what Captain Marris has pointed out-that the locking of the heart under atropin in the enteric group may be limited to a few days, the favourite period being about the tenth day.

Duodenal intubation. This was accomplished easily on the sixteenth day. The biliary fluid obtained was reported on by Major Rhea as follows: 'A clear' bilious fluid from which no organisms were grown.'

This patient had been inoculated against typhoid twice in May, 1915, but not against paratyphoid.

Bacteriological cultures from the blood, stool, and urine were negative. Agglutinations on the eighth day showed a big rise in typhoid, viz. 1 in 2,500, rising after delay to 1 in $3,6 \% 5$. On the sixteenth day the agglutinations had fallen to 1 in 2,822. Paratyphoid A and B were negative to 1 in 5.

The conclusion from these observations is an infection by the Bacillus typhosus. Investigation was made for spirochaetosis; a guinea-pig was 
injected with the patient's blood on the sixth day, but with negative results; the urine was examined twice for spirochaetes, the last time on the seventeenth day, and with negative results.

This case is of interest, for it might so easily be mistaken for either spirochaetal or catarrhal jaundice. The acute onset, lassitude and pains, the slight haemorrhage on the fifth day, the jaundice developing as the temperature fell, the shotty glands, could so justly point to spirochaetosis; and if the atropin test had not been applied till the sixteenth day the escape of the heart might have been an argument against enteric fever. On the other hand, the very brief period of fever, the flat abdomen, and the absence of splenic enlargement in the early part of the illness might well have led to a diagnosis of catarrhal jaundice. Such cases suggest the wisdom of watchfulness that a diagnosis of 'catarrhal jaundice' does not disguise enteric fever.

Case VI, Table II, is an example of jaundice complicating paratyphoid $A$. The patient was suddenly seized with pains all over the body on April 16, 1916 , and became weak and prostrate. He was sent to hospital and for the first three days of his illness he romited frequently. On the fourth day jaundice was first noticed in the conjunctivae, and during the next two days the whole body became intensely yellow. On the sixth day he complained of an aching all over the body and was rather drowsy; the jaundice was intense; the tongue was coated with a thick brown fur and there had been constipation for three days. The liver edge was felt three fingers' breadth below the costal margin. The spleen was not palpable, but may have been slightly enlarged to percussion. There were no haemorrhages, purpura, or petechiae. The urine was loaded with bile, but there was no albumin.

By the eleventh day, there was considerable improvement in the general condition and the jaundice was beginning to fade. There was never more than an evening rise of one degree of temperature $\left(99.4^{\circ}\right.$ ), and the pulse-rate varied between 54, and 72. Henceforward there was steady progress towards recovery. On the seventh day a blood count showed white blood cells 6,800 per c.mm.

Differential count :

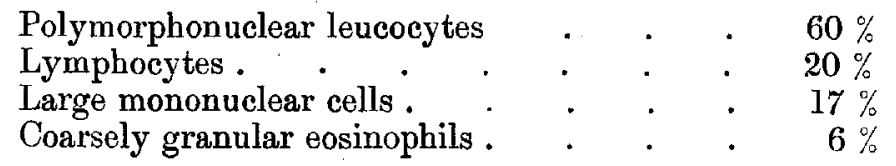

On the seventh day, after $\frac{1}{30}$ grain of atropin sulphate hypodermically, there was a moderate escape of 12 (72-84). Perhaps by the tenth day there would have been a lock, but unfortunately no further observation was made.

By agglutination this case was diagnosed as paratyphoid $\mathbf{A}$.

The following is an example of infection by the Bacillus paratyphosus B :-

Case VIII, Table II, reported sick on April 23, 1916, complaining of pains in the legs, which were so bad that he was unable to stand. Later he vomited. At the onset of the illness the temperature reached $104^{\circ}$. On the third day jaundice appeared in the conjunctivae and rapidly spread all over the body. On the seventh day the temperature was $101 \cdot 2^{\circ}$ and the pulse-rate 96 ; the patient was deeply jaundiced and drowsy and complained of a general aching. The liver extended three fingers' breadth below the ribs; the spleen could not be felt, but the splenic region was very tender.

On the eleventh day the temperature began to rise and the patient became 
worse. He was more drowsy and in a condition of misery : there were bronchitic râles throughout both lungs and the pulse was markedly dicrotic. He remained very ill for three weeks, during which he passed through a serious relapse, associated at its commencement with an increase in the jaundice.

About the twenty-first day the jaundice began to diminish and the symptoms to improve, and at the end of five weeks of illness convalescence was established.

On the seventh day the urine was loaded with bile, and showed a large cloud of albumin and a few bile-stained casts; and on the same day an examination of the blood showod white blood cells 6,100 per c.mm. and differential count:

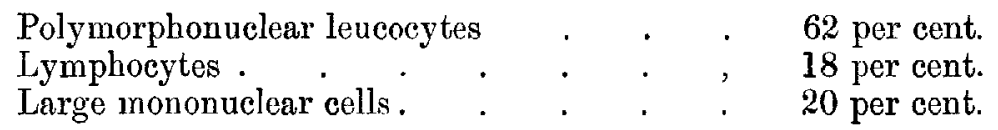

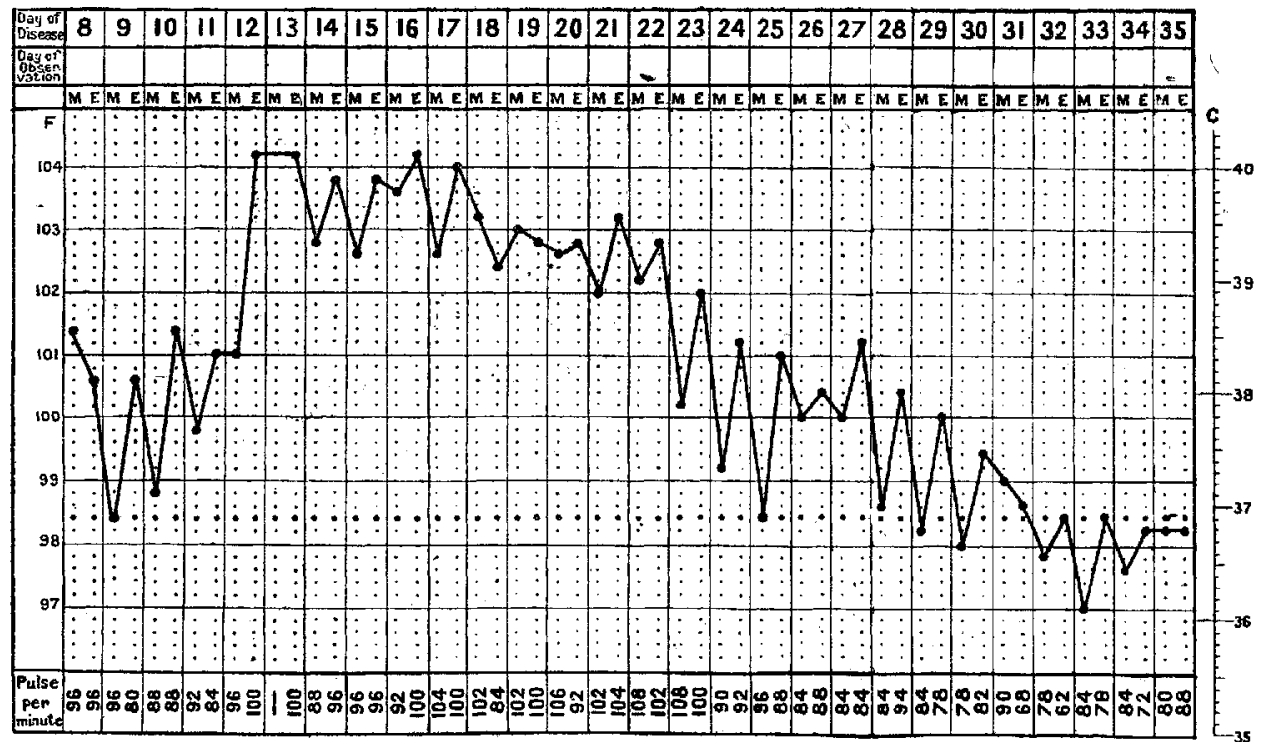

CharT IX.

Temperature Chart from Case VIII, Table II.

On the eleventh day $\frac{1}{30}$ grain of atropin sulphate was injected and the rate of the heart only quickened four beats-from 100 to 104.

Group II, in which jaundice appears later in the disease, is illustrated by the two following cases:

Case IV, Table III. On or about March 1 the patient began to suffer from headache and a feeling of weariness, and shortly afterwards was troubled with diarrhoea.

$\mathrm{He}$ was admitted to hospital about the twentieth day of his illness. He was then slightly flushed, but not 'toxic'; there were some typical spots on the abdomen; the spleen was enlarged to pereussion and the pulse was dicrotic.

On the twenty-first day the patient had a rigor; on the twenty-sixth day the conjunctivae were yellow. For eight days the fever had been high and there had been two distinct rigors. After this the temperature became normal and the general condition of the patient improved. The jaundice only lasted ten days, and during the time it was present there was some tenderness in the region of the gall-bladder. 
As the jaundice was disappearing the patient had a third rigor. After that convalescence became established.

The Bacillus paratyphosus $B$ was found in a stool and the agglutination curve was convincing. The clinical picture suggested that the gall-bladder was involved by the infection.

Case V, Table III. About March 18 this patient complained of pain in the left side. At that time he suffered much from constipation. On admission to hospital on the fifth day he was found to have a temperature of $101.2^{\circ}$, and vomited.

During the first seven days the temperature remained high (about $103^{\circ}$ ) and the patient was ill and drowsy. There was almost a complete absence of physical signs. The tongue was coated with a thick white fur, and he complained of frontal headache. On the tenth day an urticarial rash appeared on the arms and abdomen.

On the twenty-fifth day the temperature rose a little, after having been previously normal for a few days.

On the thirty-first day of disease slight conjunctival and general jaundice was noticed, which began to fade three days later, and on the twenty-eighth day had almost disappeared. Thereafter convalescence was established.

In Case X, Table III, jaundice was the first, though a late indication of illness. A nurse was admitted to hospital for a small burn. Some days later there was a tinge of jaundice and the temperature was found to be $100^{\circ} \mathrm{F}$. The pigmentation of the skin deepened and the fever continued. The spleen was not enlarged and there were no spots. The patient bad only been inoculated against typhoid and the agglutination was positive to paratyphoid $B$. Inquiry disclosed the fact that for three weeks prior to the burn the nurse had suffered from headaches, loss of energy and appetite, but had kept at her work.

What is the immediate cause of the jaundice in these cases? There must be some obstruction in the course of the biliary tree. The symptoms are not severe enough for there to be involvement of the smaller ducts within the liver. In the only post-mortem (Case IX, Table III) there is no mention of morbid change in the liver or of cholecystitis, and the gall-bladder was distended with clear bile. With the exception of Case IV, Table III, there is nothing in the clinical pictures of the cases under consideration to suggest the existence of cholecystitis. On the other hand, in most of the instances of cholecystitis complicating enteric fever which have occurred at the 14th Stationary Hospital jaundice has been absent.

The onset of the jaundice in the cases of Group I ('Table II) bears a resemblance to those spirochaetal cases in which there was obstruction at the biliary papilla.

The conclusion is that the jaundice is due to a duodenal inflammation, which, in its turn, results from the localization of the infection in the duodenum. Many of the cases described in this paper have been intubated and the duodenal fluid has contained numerous polynuclear cells of inflammation. On the other hand, typhoid and paratyphoid organisms have not been isolated from the duodenal contents at the 14th Stationary Hospital, though the results of such a search bave been positive in the hands of some continental and American observers. 
A rarer and more grave form of enteric jaundice is due to suppurative pylephlebitis, and is illustrated by the following example. ${ }^{11}$ The illness began with anorexia, abdominal pain, and constipation. On the eleventh day the temperature was $102^{\circ}$, the patient looked ill and was slightly jaundiced, and there were a few suspicious spots. The spleen was not enlarged till the twentythird day, and then it only showed an increased area of dullness.

From the eloventh day to the twenty-fifth day there was constant abdominal pain, with high fever, rising pulse-rate, increasing abdominal distension, and toxaemia.

On the twenty-sixth day a mass was felt in the right iliac fossa and jaundice was deepening. At operation a shut-off abscess was found in the appendix region. There was no abiding improvement from the operation; the fever persisted, jaundice deepened, and the patient died on the fifty-eighth day.

At the post-mortem there was peritonitis; Peyer's patches were prominent, but there was no ulceration. The appendix was long and the last half-inch was gangrenous. The liver was enlarged and riddled with small abscesses. The gall-bladder was not enlarged, but its wall was thick and the bile was clear. One liver abscess had penetrated the right diaphragm towards the end of life, and had caused an abscess in the lower lobe of the right lung.

During life, one blood culture, three stool cultures, and one urine culture were all negative; yet post-mortem cultures from the gall-bladder and from an abscess in the liver grew Bacillus paratyphoid $B$ in pure culture.

(C.) 'Catar'rhal' jaundice. There have becn many cases scattered through the hospitals conforming to the features associated with the loosely employed title ' catarrhal' jaundice. Some of them have resembled the symptoms of those described in the foregoing series, from which they have been excluded by negative bacteriological findings. For instance, a patient in the next bed to Case III, Table III, presented the same clinical picture, except that the latter had an enlaryed spleen and the former had not. The latter was bacteriologically positive (paratyphoid B), and the former was negative.

'Catarrhal' jaundice has the features of an infection-either a mild blood infection which has localized in the duodenum, or less often perhaps an infective gastritis which has extended to the duodenum. It is a convenient term to describe a jaundice in which the infective agent has not been discovered. The usual symptoms are-headache, lassitude, a transitory mild fever, discomfort in the upper abdomen, anorexia and nausea, with jaundice supervening later. No doubt the same infections can exist without the jaundice.

There have been examples of the well-known association between jaundice and influenza and lobar pneumonia. One case occurred during the peeling stage of scarlet fever. On the twenty-fifth day the temperature rose suddenly from normal to $102^{\circ}$, and there was anorexia with abdominal discomfort. The following day the temperature had returned to normal, but the patient was jaundiced and remained so for nine days.

The following is an example of an undetermined infective jaundice, and as the case was thoroughly worked out it is worth giving in some detail :

Onset was gradual with chilliness, fever, weakness, anorexia, abdominal pain, and vomiting. On the fourth day patient declared sick and the temperature was $108^{\circ}$. On the fifth day the temperature was normal and jaundice appeared. The upper half of the abdomen was tender and the spleen could be felt for $1 \frac{1}{2}$ inches below the costal margin. The jaundice rapidly became deep, but,

11 Dawson and Whittington, Quart. Journ. Med., Jan., 1916. 
though apathetic, the patient never was toxic. The urine contained bile and a trace of albumîn.

On the ninth day the jaundice was slightly less. On the tenth day there was a return of fever and the spleen remained palpable, but there was no deepening of the icterus. The temperature did not finally settle till the eighteenth day; the jaundice and the enlargement of the spleen had disappeared on the twentieth day, and by that time convalescence was established.

The atropin test was made twice-on the sixth day, when there was an escape of $20(60-80)$, and on the fifteenth day, when there was an escape of $16(66-82)$.

Agglutinations were tested three times-on the ninth, fourteenth, and nineteenth days. They were negative to paratyphoid $A$ and $B$, and typhoid remained constant at 1 in 125. The patient had been inoculated against typhoid only two years previously.

A blood culture was made during a relapse of fever and two cultures, each from urine and faeces, were negative to the enteric group. On two occasions the urine was thoroughly searched for spirochaetes, but with negative results.

The fasting stomach and duodenum were intubated. Cultures from the gastric contents were negative, while those from the duodenal contents showed a growth of a Gram-negative coccobacillus. The characters of this bacillus were tested by putting it through broth, gelatine, agar, litmus milk, litmus whey, peptone, and the sugars. Litmus milk and whey became alkaline in twenty-four: hours without clot formation in the former. The sugars were not acted upon, with the exception of glucose, from which acid without gas was formed after forty-eight hours' incubation.

This coliform organism was the sole positive result from the investigations. It was not agglutinated by the patient's own serum, though this is not conclusive against specificity. Was this organism the cause of the illness? Coliform organisms are known to be associated with cholecystitis and gallstone formation, why not with duodenitis and cholangitis?

It is doubtful if coliform organisms exist normally in the duodenum. Proof that this organism was the cause is, however, lacking, The alternative explanation is that the patient had enteric fever. The bacteriological findings are against this view. That, however, cases of enteric fever do occur in which the most careful and repeated bacteriological investigations are negative, is undoubted. An example is afforded by the case of pylephlebitis above described.

Diagnosis (Early). An initial difficulty arises from the fact that so many infections have the same symptoms at the commencement of the illness. Given a patient who has head and body aches, chilliness, fever, vomiting, and he may have one of many infections, e.g. enteric, trench fever, spirochaetosis, influenza, Micrococcus tetragenus, amongst others determined or undetermined. The difficulty is less if the onset is gradual, for that would suggest enteric or spirochaetosis. Both these diseases, however, can commence abruptly; and as regards enteric the proportion of sudden onsets is increasing. Earlier in the war the gradual onset was about twice as frequent as the abrupt one, whereas recently this proportion has changed. Thus an analysis of 136 recent cases shows :

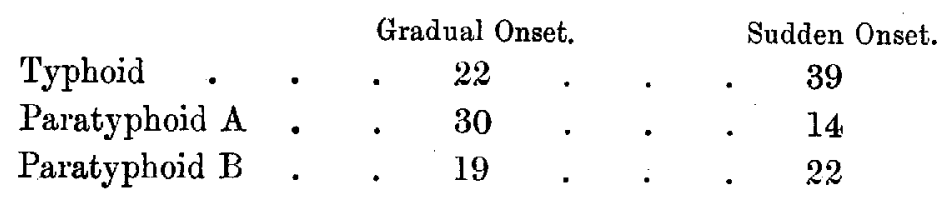


As regards influenza, a tentative early opinion can be formed, for the disease seldom exists without the characteristic catarrhal manifestations in the upper respiratory tract. It is relatively uncommon in the Expeditionary Force.

Trench fever gives no distinguishing early picture. The characteristic temperature chart and leg pains need to be observed before an opinion can be formed.

Tetragenus infection, if alone, would seem to run but a short course of three or four days.

No doubt if blood cultures could be taken promptly, positive results would be forthcoming in a proportion of cases; but this is impossible where patients are numerous and conditions difficult.

Some assistance in determining the group to which a case of jaundice belongs may be obtained by studying the result on the rate of the heart of the injection of atropin sulphate. This method of differentiating between 'fevers' belonging to the enteric group and other 'fevers' was suggested by Captain Marris, R.A.M.C., who is publishing a preliminary report on his work. During an investigation of the cardio-vascular conditions in the enteric group, he found that the heart-rate did not usually quicken after the administration of $\frac{2}{50}$ grain atropin, as the normal heart does. If atropin sulphate, $\frac{1}{50}$ to $\frac{1}{30}$ grain, is given hypodermically to a normal person, after an interval of 15-20 minutes the rate of the heart will increase to 20-25 beats per minute. Captain Marris found that for a variable period during the course of typhoid or paratyphoid fever the heart either failed to quicken at all or did so very little after the hypodermic injection of $\frac{1}{30}$ grain atropin sulphate. After the study of a large number of cases, he is of opinion that the poison of the enteric organisms prevents the heart responding to the action of atropin, and that this effect is most marked between the eighth and. fifteenth days of the disease. The effect may be very evanescent, and may only be present on one or two days; for instance, Case IV, Table II, described above.

The mothod of administration is as follows: The patient lies absolutely quiet, and ought not to be disturbed during the experiment. The pulse-rate is counted two or three times, and when it is found that the rate remains constant, $\frac{1}{50}$ or $\frac{1}{30}$ grain atropin sulphate is injected hypodermically. The rate of the pulse is then counted at intervals of five minutes for an hour. Normally at first there is frequently some slowing of the heart-rate, and then the speed quickens, usually increasing by $20-30$ beats per minute. The higher rate is usually maintained for about a hour, and then gradually falls back to the normal.

Charts VI and VII (p. 110) show the results of two experiments. In one the rate of the heart was only increased by four beats, and this 'locking' suggested that the particular case of jaundice was suffering from typhoid or paratyphoid fever. The agglutination curve was typical of $B$. typhosus infection.

In the second the heart 'escaped', and increased its speed by 30 beats after the injection of atropin sulphate. This quickening under the influence of atropin made it probable that the patient was not suffering from any member of the enteric group, and spirochaetes were found in the urine.

After a considerable experience in the use of atropin in the study of bradycardia and other arrhythmias, and recently in the more special sphere 
suggested by Captain Marris, we are convinced of its utility as an aid to diagnosis.

The appearance of jaundice after the tenth day is consistent with enteric fever, but not with spirochaetosis. On the other hand, jaundice may appear early in both diseases, which sometimes present closely resembling clinical pictures (e.g. Case IV, Table II). With the diminished frequency of spots in enterie, their absence is of correspondingly diminished significance. To the minds of those who see many cases of pyrexia a palpable spleen suggests enteric (provided malaria can be excluded), because in this disease it is relatively so much more common. If one may judge, however, by this series of enteric jaundices the palpable spleen is becoming less frequent, for it is only present in four out of twenty-six cases. In spirochaetosis it is certainly unusual-only two out of eighteen cases in our series (Table I).

The slowness of the pulse in proportion to the fever is a feature common to both enteric and spirochaetosis. The blood pressure in typhoid and paratyphoid is commonly 100 to 105 (systolic), which is low in comparison with other infections.

Leucopenia cannot be depended on as evidence of enteric. It is probably only present at the beginning of the illness, and is not even constant. Note, for instance, Case IV, Table II, in which on the eighth day the white cell count was 23,000 .

Herpes labialis is evidence in favour of spirochaetosis, in which, however, it is not always present. Epistaxis may oceur in either enteric or spirochaetosis, but haemoptysis, haematemesis, melaena, or purpura are strongly suggestive of spirochaetal infection.

Here again it must be remembered that in the milder cases of the latter this valuable bit of evidence is often absent.

The presence of herpes or haemorrhage in an early stage of any fever would suggest the injection of 5 c.c. of the patient's blood into a guinea-pig, even if jaundice had not appeared, bearing in mind that spirochaetosis exists without jaundice, though how often we do not as yet know. To be effective inoculation of the guinea-pig has to be done before the fifth or sixth day. This limits its application; and further, guinea-pigs are not always available.

The finding of spirochaetes in the urine may be relied upon, though perhaps two or three examinations at intervals may be necessary. An effective method is to draw off 20 c.c. from the lower stratum of a urine which has been standing, spin for ten minutes, pour off the top fluid, replace it with distilled water, shake and spin again; repeat the process; then make smears from the final deposit and stain with Fontana. Plate 15, B, shows a variety of spirochaetes from one of these urines. To avoid error Lieutenant Bedson examined control urines from cases of other diagnosed fevers. In one case he found spirochaetes, shown in Plate 16, A, which are morphologically distinguishable from the specific spirochaete under discussion; they are broader and have a distinctive and constant shape.

Reverting to enteric jaundice, the bacteriological findings call for some 
comment. It is to be noted how comparatively seldom the organisms are found, viz. in seven out of twenty-six cases. If the patients had been triply inoculated this would perhaps be in accordance with expectations, for the modified infection would be likely to discharge fewer bacilli into the urinary and intestinal tracts.

But of the nineteen cases of paratyphoid A and B, only two had been so inoculated, and yet the organism was only found in seven cases. Apart from inoculation it may be because the infection is milder. ${ }^{12}$

Under such circumstances the bacteriological diagnosis has to be based on the variations of the agglutinations on three or four occasions, separated by periods of four or more days.

There is no doubt that the reliability of agglutination has been greatly enhanced by the technique of Professor Dreyer, and that as a means of diagnosis its value is great. Where the variations in the agglutinations are marked-say, for example, $1,200,3,675,2,822-1,534$ in typhosus-surely no one would doubt the conclusion.

Where such variations of reading are less marked, and especially if the agglutinations in the paratyphoid members of the family simultaneously show disturbance, correct inference is more difficult.

On what degree of variation can a positive diagnosis be based? The answer to this question is the more important where the clinical manifestations are ill-defined or anomalous. Out of this another question arises. In patients who have been inoculated against enteric, do other fevers affect the agglutination curves? Further work is needed before a final answer to this question can be given. The importance of it is illustrated by the following case: The patient was suddenly seized with generalized pains, prostration, and headache. The temperature was $102^{\circ}-103^{\circ}$ for two to three days, and on the fifth day ho became jaundiced and rather drowsy. About the fourth or fifth day herpes on the lips appeared.

On the tenth day the patient was still apathetic and very yellow; there was a diffuse purplish macular rash all over the chest and abdomen; the liver was enlarged and the edge of the spleen was just palpable; the temperature was subnormal, and the pulse-rate was 96 . Thereafter the symptoms abated, and the patient gradually recovered.

On the sixth day of illness a guinea-pig was inoculated with the patient's blood, but did not develop jaundice. Spirochaetes were found in the urine on the eleventh day, and in abundance.

The following figures show the result of the agglutinations to paratyphoid $\mathrm{A}$ in this case :

\begin{tabular}{|c|c|c|}
\hline Date. & & Agglutinations to A. \\
\hline 27.8 .16 & - & 160 \\
\hline 1. 9.16 & - & 1,300 \\
\hline 8. 9.16 & - & 640 \\
\hline 13. 9.16 & . & 600 \\
\hline
\end{tabular}

${ }^{32}$ Most of the cases of typhoid and paratyphoid fevers now occurring in the Expeditionary Force are so mild as to present a clinical picture notably dissimilar from that usually associated with the term Enteric Fever. 
On the agglutination curve the Bacteriological Department reported that the patient was suffering from paratyphoid $\mathrm{A}$ fever.

The question arises as to which infection was the cause of the patient's illness. Clinically, the case had more the appearance of spirochaetal than of enteric jaundice. The typical spirochaetes were demonstrated in the urine. Was it a case of mixed infection or were the agglutinations being influenced by the spirochaetal infection?

Considering that these varieties of jaundice might be due to a duodenitis, attempts were made to obtain organisms directly from the duodenum, by means of intubation with an Einhorn's tube. The perforated metal capsule and attached tube were sterilized and filled with sterile water; the capsule was then coated with a thin layer of specially prepared fat which would only dissolve in alkaline duodenal juice. $^{13}$ In this way contamination while swallowing is prevented. It is necessary that the patient's stomach should be empty at the time of the intubation. After an interval of fifteen to thirty minutes an alkaline bilious fluid can be sucked up by a syringe, or siphoned off. If there is delay, the fatty covering of the capsule can be blown off by pressure from a syringe attached to the tube. The fluid so obtained is used for investigation.

In this way many cases of spirochaetal and enteric jaundice have been examined.

In no case has an organism bearing the peculiar characteristics of Bacillus typhosus, paratyphosus $A$ or $B$, been obtained by this method. However, various coliform organisms have been isolated, and occasionally also staphylococci and streptococci.

Samples of duodenal contents withdrawn from patients suffering from spirochaetal jaundice have on numerous occasions shown the presence of polymorphonnclear leucocytes and large mononuclear cells. These cells were obviously the result of local inflammation.

With regard to the types of jaundice here described, a correct diagnosis can usually be arrived at by a consideration of all the data, though some of the cases, and especially the milder ones, do present difficulties.

It is a great pleasure to acknowledge the help which we have obtained from others in the investigation of our cases.

The bacteriological work has been done by the staff of the 14th Stationary Hospital under the directorship of Lieut.-Col. Gratton, R.A.M.C., and now under Capt. Perry, R.A.M.C., by Lieut. Bedson, R.A.M.C., and by Major CarmaltJones, R.A.M.C. Dr. C. H. Browning has been generous with his knowledge. For the specimens and drawings of spirochaetes we are indebted to Lieut. Bedson. The coloured illustrations are a high tribute to the skill of Mr. Shiells and Mr. Ford.

${ }^{13}$ Prepared by Mr. H. Hurlstone, Ph.C., of Bell and Croyden. 


\section{APPENDIX.}

A case which has come under observation too recently to be incorporated in the text is of sufficient importance to be briefly described here.

The illness began suddenly with head and body pains, wealnness, and chilliness. On the second and third days there was repeated vomiting. On the first three days the temperature varied between $102.4^{\circ}$ and $100.2^{\circ}$. On the third day herpes appeared round the mouth and jaundice was noticed; on the fourth day the temperature fell to normal and the jaundice rapidly deepened. On the fifth day there was coffee grounds vomiting, the urine contained much albumin and epithelial and erythrocytic casts, but no spirochaetes. The patient had become very ill with a dark brown tongue, and had a tonic convulsion during which he became pale and almost pulseless. On the subsequent days epistaxis, haematemesis, melaena, and purpura occurred, and death ensued from toxaemia and anaemia on the twelfth day. There was no return of fever after the temperature fell on the fourth day. Early in the illness the stools contained bile; later they were clay-coloured or black, due to altered blood.

The blood pictures were as follows:

\begin{tabular}{|c|c|c|c|}
\hline On the 8th day: & Red cells & & $4,480,000$ \\
\hline & White cells & & 12,000 \\
\hline & Differential count: & Polymorphonuclears & 64.3 per cent \\
\hline & Lymphocytes & . . . . & 28.1 per cent \\
\hline & Mononuclears & • & 3.7 per cent \\
\hline & Eosinophils & • & 0.9 per cent \\
\hline & $\begin{array}{l}\text { No nucleated reds } \\
\text { No polychromasia. }\end{array}$ & poikilocytes. & \\
\hline t & Red cells & . & $1,815,000$ \\
\hline & White cells . & . & 32,000 \\
\hline & Differential count: & Polymorphonuclears & 97.3 per cent. \\
\hline & Lymphocytes & $. \quad . \quad$. & 1.8 per cent \\
\hline & Mononuclears & . & 0 per cent \\
\hline & Eosinophils & . & 0.9 per cent. \\
\hline
\end{tabular}

No nucleated reds.

Some poikilocytes.

Some polychromasia.

The urine contained the characteristic spirochaetes on the twelfth day, but none at the first examination on the sixth day.

A guinea-pig was inoculated with 5 c.c. of urine on the seventl day, but with negative results. The agglutinations were negative to enteric fever.

At the autopsy the appearances were identical with those described in Cases II and IV. The stomach and small intestine contained much blood of gastro-duodenal origin. The stomach and duodenum were accurately pictured by Plate 10, and the common bile duct when opened by Plate II. The last half-inch of the duct was swollen and of bluish colour, in resemblance to the duodenum and in contrast to the rest of the duct. Before the common bile duct was opened a probe passed into the duodenum dislodged a formed plug which was impacted in the ampulla. A film made from this plug showed numerous epithelial cell nuclei embedded in a matrix of mucin. The appearances suggested an obstructed papilla, and such obstruction would be favoured by the epithelial folds within the ampulla (Plate 14).

The liver was normal in size, yellowish green, and slightly friable; its lobular pattern was distinct: a film made from a scraping showed one characteristic spirochaete.

The gall-bladder was of normal size and contained very viscid bile. The kidneys showed marked changes; the pattern was blurred and the cortex was swollen, and showed yellow opaque alternating with dark brown areas. Cultures taken from the gall-bladder and spleen were negative to enteric fever.

The minute anatomy of the liver resembled that of the early cases, as illustrated in Plate 13. Thus, there was no striking alteration in the trabecular arrangement of the cells and variations in the size of the nuclei were not marked; mitoses were scanty. On the other hand, there was clear evidence of bile stasis, as already described. Large clear vacuoles were seen in a number of liver cells near the centres of lobules; but staining with Sudan III did not show the presence of fat anywhere. In one place a hepatic venule was seen to be filled with a mass of dissociated liver cells mingled with red blood corpuscles. 
TABLE I

No.

History.

Condition on Admission. Jaundice.

Abdominal

Liver.

I. Nov. 10. Faint and drowsy. Nov.15. Bowels not opened Vomited

Nov. 12. Bile in urine (water like blood)

Nov. 13. Reported sick

7 days. Distension of abdomen. Very drowsy and ill. Very furred tongue

II. Dec. 16. Sudden chill. Dec. 24. Round worm from Headache. Fever pains in thigh. Nausea

stomach. Melaena. Vomiting and nausea marked

Dec. 29. Asthenia and convulsions. Death

III. Dec. 10. Ill for 9 days. Dec. 26. Dyspnoeic. Great Diarrhoea and vomiting.

Dec. 12. Reported sick. Pains in legs and haematemesis

Dec. 19. Jaundice

IV. Nov. 3. Pains in small of Nov. 28. Jaundice noticed back and chest

Nov. 13. Sore throat

Nov.14. Suddenly vomited. Very ill and vomiting till 28th abdominal distension

Marked universal

Considerable

3 fingers' breadth

Marked on 5 th day. Spasms often across epigastrium. Drowsy. Headache and constipation

V. Dec. 20. Reported sick : incontinence of urine Dec. 25. Jaundice. Shivering and coughing

Dec. 26. Epistaxis

VI. Jan. 20. Vomited every- Jan. 28. Heartburn. Petething

Jan. 22. Reported sick. Jaundiced

VII. Nor. 19. General pains. Giddiness

Nov. 24. Sickness and vomiting

Nov. 25. Jaundice. Green vision

VIII. Nov. 6. Weak and misty eyes. Headache

Nov. 13. Reported sick

Nov. 16. Jaundice

chise on abdomen and legs

Dec. 27. Cough. Sleepless. Headache. Bronchitis

Marked universal

2 fingers'

Epigastric

distension

lessened by

enema.

Epigastric

pain

3 fingers' breadth

universal

Very tender

abdomen

breadth

None

3 fingers' breadth

Moderate

Some disten-

Nil

sion. No

tenderness

Marked

Distended and

Nil

Nov. 29. Drowsy. Haemoptysis. Melaena

universal

tender

Very

Epigastric

3 fingers'

laemic. Tongue brown fur. Haemoptysis. Crepitations in third left intercostal space

IX. May 10, Pain in head and at back of eyes

May 16. Jaundice. Epi-

May 23. Dry tongue. Fading jaundice
Fading universal
Nil

intense tenderness breadth

Epigastric pain staxis 


\section{TABLE I}

\begin{tabular}{|c|c|c|c|c|c|c|c|}
\hline \multirow[t]{2}{*}{ Spleen. } & \multicolumn{3}{|c|}{ Blood. } & \multicolumn{3}{|c|}{ Urine. } & Stools. \\
\hline & $\mathrm{Hb}$. & R. B.C. & W. B. C. & Bile. & $\begin{array}{l}\text { Albu- } \\
\text { min. }\end{array}$ & Casts. & \\
\hline Nil & 100 & $5,200,000$ & $\begin{array}{l}13,000 \\
\text { P.M.N. }=63 \\
\text { Lymph. }=33 \\
\text { Eosin. }=4\end{array}$ & ++ & $\begin{array}{l}\frac{1}{10} \text { test- } \\
\text { tube }\end{array}$ & $\begin{array}{l}\text { Hya- } \\
\text { line } \\
\text { and } \\
\text { granu- } \\
\text { lar }\end{array}$ & $\begin{array}{c}\text { Some } \\
\text { bile }\end{array}$ \\
\hline $\mathrm{Nil}$ & & & $\begin{array}{l}34,000 \\
\text { P.M.N. }=93 \\
\text { Large } \\
\text { Mono. }=1 \\
\text { Lymph. }=6\end{array}$ & ++ & $\begin{array}{l}\frac{1}{10} \text { test- } \\
\text { tube }\end{array}$ & $\mathrm{Nil}$ & $\begin{array}{l}\text { Light } \\
\text { yellow }\end{array}$ \\
\hline
\end{tabular}

$$
\begin{aligned}
& 22,500++ \text { Trace }++\frac{\begin{array}{c}
\text { Almost } \\
\text { clay- } \\
\text { coloured }
\end{array}}{12,400++\begin{array}{l}
\frac{1}{9} \text { test- Granu- } \\
\text { tube }
\end{array} \text { lar }} \underset{\text { brown }}{\text { Light }}
\end{aligned}
$$$$
10,000+\mathrm{Nil} \text { Nil }
$$$$
12,500++ \text { Trace }
$$$$
\text { Nil }
$$

Light brown
Pain in

Back and

Limbe.

Progress.

Slight Nov, 27. Gall-bladder opened and drained for 14 days

Dec. 18. Jaundice disappeared.

Dec. 30. England

Pains in Dec. 29. Died

thighs

Nil Jan. 9. Died

Nil Dec. 1. Died

General Marked secondary pain and fever lasting 23 days tender- Jan. 29. England ness in thighs and calves

Nil No secondary fever Feb. 16. England

Tender No secondary fever calves Dec. 23. England

Nil

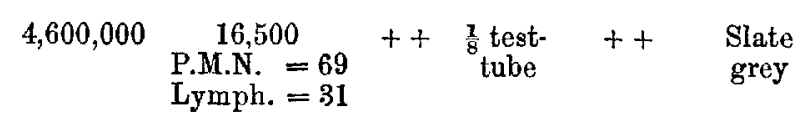

Abdo- Dec. 23. England men and Secondary fever for thighs 10 days

Marked Secondary fever for 4 days May 31. England 
TABLE I (continued)

No.

History.

Condition on Admission. Jaundice.

Abdominal

Tenderness.

Liver.

X. Nov. 21. Sudden vomiting

Nov. 24. Vomiting. Haema-
Nov. 29. Anorexia. Furred temesis. Melaena. Jauntongue

Moderate universal dice
Cramping 2 fingers'
pains in
upper abdo-
men

$\begin{array}{cc}\text { Epigastric } & 3 \text { fingers' } \\ \text { tenderness } & \text { breadth }\end{array}$

Tenderness of 3 fingers' upper abdo- breadth men

Slight $\quad \begin{gathered}3 \text { fingers' } \\ \text { breadth }\end{gathered}$

Feb.22. Epistaxis.Anaemia. Marked Loss of flesh

Marked universal

Nil

Nil ptysis. Vomiting. Purplish discoloration of skin

May 15. Cough and haemoptysis

May 19. Jaundice

XV. Aug. 7. Sudden diarrhoea Aug. 9. T. $=101^{\circ}$. Melaena. Marked prostration

Aug. 14. Haemoptysis

Aug. 16. Marked jaundice. Basal crepitations. T. = $101.2^{\circ}$. Tongue dry, furred

Wellmarked universal. Aug. 26. Fading rapidly. Sept. 1. Almost gone

XVI. June 9. Felt seedy June 10. Reported sick. $\mathrm{T} .=103^{\circ}$. Pains in legs and weakness

June 13. Jaundice

XVII. June 15. Sudden pains all over. Headache. Vomiting. T. $=102^{\circ}$

June 15-21. Weak. Anorexia. Vomiting

June 21. Jaundice

XVIII. July 9. Sudden vomiting July20. Drowsy.Bronchitis. and prostration. T. $=$ $103^{\circ}$

June 16. Marked jaundice. Drowsy. Occasional vomiting. Slight abdominal distension

Wellmarked universal

Slight in Hand's right hypo- breadth bechondrium low costal margin

General

Slight across 3 fingers'

June 24. Jaundiced and drowsy. Feeling miserable. Tongue dry, brown marked epigastrium breadth

General marked Marked in 3 fingers'
right hypo-
chondrium Haemoptysis. Dyspnoea.

July 9-16. Prostration. Vomiting. Photophobia. July 16. Jaundice 
TABLE I (continued)

Spleen. $\quad$ Blood. Urine. Stools. $\begin{gathered}\text { Pain in } \\ \text { Backand } \\ \text { Limbs. }\end{gathered}$ Progress.

Hb. R.B.C. W.B.C. Bile. $\begin{gathered}\text { Albu- } \\ \text { min. Casts. }\end{gathered}$

\section{Dullness to rib margin}

Nil

Nil
Slate
grey

Pains abdomen and

thighs.

Paraes-

thesia

left foot

Nil Auricular fibrillation

Hya- Yellow line brown and granu-

Nil

$40 \quad 2,160,000$

$20,000++\quad+$

5,000

$$
++ \text { Trace }
$$

Granu-

Yellow
brown

Very marked

in legs

+ Trace Nil

Nil

$75 \quad 4,400,000$

Pains in March 6. England
legs

P.M.N. $=67$
Lymph. $=85$

Large

Monos. $=5$

Eosin. $=3$

Not

palpable

$80 \quad 4,860,000$

24,000

$++$

Consider-

$\frac{1}{8}$ test- Granu-

mucoid

able

Not felt

Not felt

$$
\begin{gathered}
13,000 \\
\text { P.M.N. }=82 \\
\text { Lymph. }=10 \\
\text { Large } \\
\text { Monos. }=5 \\
\text { Eosin. }=\mathbf{2}
\end{gathered}
$$$$
+t \text { Trace }
$$

yellow yellow

P.M.N. $=73$

Lymph. $=23$

Hosin. $=4$

++ None

None

Not felt
Bile-

coloured blood (2)

Light

brown

Light brown

brown

Present Spirochaetes found in the urine

Aug. 21. Fingland

Marked Spirochaetes found in June 22. England

Marked Spirochaetes found in the urine

June 28. England

Light brown

Slight Spirochaetes found in the urine July 24. England 


\section{TABLE II}

No. Onset of Illness.

On Admission.

Jaundice.

Liver.

I. Mar. 31. Sudden abdominal Apr. 8. Jaundice. Drowsy pain. Vomited and ill

Marked 3 fingers'

(8th day) breadth

II. Sept. 23. Sudden headache. Sept. 31. Heavy; tlushed. Giddiness. Weakness

Slight jaundice

Slight

(8th day)

Nil

III. Oct. 23. Sudden headache. Nov. 8. 'Rather ill,' T, = Pains in lower legs $98^{\circ}$

Jaundice

(10th day)

Nil Nov. 2. Frequent vomiting. Jaundice

IV. Aug. 27. Sudden headache. Aug. 30. Vomiting. Icterus Prostration Aug. 28. T. $=103 \cdot 6^{\circ}$

4th day 3 fingers' breadth

V. Jan. 30. Sudden shivering. Feb. 2. Very toxic. Upper Very marked Anorexia abdomen tender (2nd day)

3 fingers' Feb. 1. Jaundice

Very marked 3 fingers'

(4th day) breadth

Apr. 20. Early vomiting.

Apr. 22. Drowsy

VII. Aug. 1. Sudden headache Aug. 8. Jaundice and vomiting

6th-7th day

$?$ VIII. Apr. 23. Sudden pains in Apr. 30. Heavy. T. $=101^{\circ} \begin{gathered}\text { Very marked } \\ \text { (4th day) }\end{gathered} \begin{gathered}3 \text { fingers' } \\ \text { breadth }\end{gathered}$
legs. Vomited Apr, 26. Jaundice

IX. Oct. 19. Gradual abdominal Oct. 29. Indefinite malaise pain. Vomited. Few days later jaundice

Faint (early) Tenderness only

X. May 20. Acute general pains. May 26. Headache. Cyano. 6th day Nil $\mathrm{T} .=102^{\circ}$. No spots sis

Few days only at outset

XI. Feb. 24. Gradual seediness. Mar. 3. T. $=103^{\circ}$. HeadHeadache. Vomiting Feb. 28. Jaundice ache. No jaundice noted. Nausea

XII. May 3. Sudden pain in May 13. Jaundice. Epi- 7th day-9th abdomen staxis

May 4. Headache. General pains

day, dis-

appearing

Not men-

$$
\text { pains }
$$

XIII. Feb. 14. Gradual giddiness. Shivering. Epistaxis Feb. 22. Slight jaundice

Mar. 3. Slight jaundice. No spots
Sth day, Not men- slight tioned

XIV. Aug. 20. Sudden headache. Aug. 24. Bronchitis No other pain. No vomit- Aug. 26. Jaundice ing. No diarrhoea

6th day, moderate tioned 


\section{TABLE II}

\begin{tabular}{|c|c|c|c|}
\hline Spleen. & Inoculation. & Bacteriology.* & Progress and Remarks. \\
\hline $\begin{array}{c}\text { Much } \\
\text { enlarged }\end{array}$ & Feb. $/ 15$. T. V. $\dagger+2$ & (6) Falling titre in $\mathrm{T}$. & Duration of illness 33 days \\
\hline Nil & Oct./14. 'T. V. +2 & (4) Falling titre in $\mathrm{T}$. & $\begin{array}{l}\text { Duration of illness } 43 \text { days. } \\
\text { Fever of relapse, } 15 \text { th- } \\
\text { 23rd days }\end{array}$ \\
\hline
\end{tabular}

Duration of illness 44 days

Nil till 15th palpable

Palpable

Nil

$?$

Not mentioned

Nil Nov./14. T. V. +2
Dec./14. T. V. +2

$\mathrm{May} / 16$. T. A. B. $\dagger$
May/15. T. V. +2

Aug./15. T. V. +2

June/15. T. V. +2
(3) Rising titre in T', up to 1 in 3,125

(7) Very variable titre in A

Duration of illness 60 days. Fever of relapse, 10th26 th days

(3) Variable titre in A. Blood culture A

Duration of illness 25 days

(4) Rising titre in A

(4) High and variable titre Duration of illness 61 days in B. Blood culture B

(3) Small titre in B. 1 in Duration of illness 28 days $25 ; 1$ in 80 ?

Nil T. V. +7. 3.4.16. T. A. B.

(4) Variable titre in B

Duration of illness 48 days. Fever of relapse, $24 \mathrm{th}-$ 33rd days

Nil

T. V. + 2. Aug. $/ 14$ and June/15

(4) Variable titre in B

Duration of illness 37 days

Nil

Sept./15. T. V. +2

(3) Variable titre in $\mathrm{B}$

Duration of illness 51 days. Fever of relapse, $27 \mathrm{th}$ 33rd days (very slight)

Nil Sept. and Oct./14. T. V. +2

(4) Aggl. 1 in 20 in B

Duration of illness 37 days

Nil

Duration of illness 23 days.
At commencement was
picture of bronchitis and jaundice

* In the column Bacteriology the left-hand numerals indicate the number of agglutinations observed. + T. V. = Typhoid. T. A.B. = Typhoid and paratyphoid A and B. 
TABLE III

No. Onset of Illness.

I. July 10. Gradual onset with tonsillitis

II. Jan. 2. Sudden colic. Diar- Jan. 20. Drowsy rhoea. Few small spots

III. Sept. 22. Gradual onset with Oct. 3 (19th day). Temperadiarrhoea ( 5 days). Headache. Temperature and abdominal pain

IV. Mar. 1-7. Gradual headache. Mar. 26 (20th day). 3 spots Fever. Diarrhoea. One typical spot V. Mar. 17. Gradual pain in left
side. Constipated. Headache. T. $=101 \cdot 2^{\circ}$. Vomited

VI. Oct. 12. Gradual headache. Lassitude

On Admission.

July 27. Recently yellow ture normal on abdomen Apr. 1. Tongue thick fur.
No spleen enlargement. Frontal pain

Oct. 25. T. $=102 \cdot 8^{\circ}$. Drowsy and ill
VII. Oct. 20. Gradual headache. Nov. 10. Sallow. Slight Weakness and constipation. Several large spots

VIII. Aug. 27. Gradual headache. Sept. 7. Jaundice General pains. Epistaxis IX. No history on notes.
Gradual ?

X. Aug. 5. Gradual headache.
Lassitude. Able to work for 3 weeks

Apr. 29. Admitted very ill.

Aug. 22. Admitted for a burn Aug. 26. Jaundice and mild

XI. June 5. Sudden headache. June 22. No physical signs, Vomiting June 22. Slight jaundice. Large number of spots

XII. May 3. Sudden vomiting. May 10. Drowsy Faints. Headache. No spots jaundice $T,=101^{\circ} . P .=130$. Acute pneumonia pyrexia for 3 following weeks

\author{
Jaundice. Liver. \\ 17th day or Enlarged \\ previously \\ 18th day T'ender- \\ gall-bladder \\ Moderate \\ Nil \\ noticed 12th \\ day
Apr. 1 (26th
day) first
noticed \\ Gall- \\ bladder
}

Apr. 18 (31st

day) till Apr.

Nil

$\begin{array}{cc}\text { 21st-25th } & \text { Not men- } \\ \text { days slight, } & \text { tioned } \\ \text { with pyrexia } & \end{array}$

21st day Not men-

tioned

11th day

Nil

May 3

slight

21st day

moderate

Nil

17th day

Nil except jaundice

19th day

slight 
TABLE III

\begin{tabular}{|c|c|c|c|}
\hline Spleen. & Inoculation. & Bacteriology. & Progress and Remarks. \\
\hline Nil & 27 July/15, T. A. B. & (4) Varying titre in 'T. & Duration of illness 19 days \\
\hline Nil & ... & Jan. 31. T. from stool & Duration of illness 40 days \\
\hline Palpable & Feb. $/ 15$. T. V. +2 & (2) Aggl. 1 in $2,550 \mathrm{~A}$. & $\begin{array}{l}\text { Duration of illness } 40 \text { days. } \\
\text { Fever of relapse, } 15 \text { th- } \\
\text { 26th days }\end{array}$ \\
\hline Enlarged? & $\ldots$ & $\begin{array}{l}\text { Mar. 31. B from stool. } \\
\text { Titre }+ \text { in B }\end{array}$ & $\begin{array}{l}\text { Duration of illness } 65 \text { days. } \\
\text { Relapse of fever for } 5 \text { days }\end{array}$ \\
\hline Nil & Oct. $/ 14$. T. V. +2 & (4) Falling titre in B & $\begin{array}{l}\text { 21st-28th days, small re- } \\
\text { lapse, with jaundice }\end{array}$ \\
\hline Nil & Feb. $/ 15$. T. V. +2 & Nov. 7. B from stool & $\begin{array}{l}\text { Duration of illness } 63 \text { days. } \\
\text { Fever of relapse, 33rd- } \\
39 \text { th days }\end{array}$ \\
\hline $\mathrm{Nil}$ & June/15. T. V. + 1 & $\begin{array}{l}\text { Nov. 13. B from stool } \\
\text { Dec. 4. B from urine }\end{array}$ & Duration of illness 69 days \\
\hline Nil & $\operatorname{Jan} . / 15 . \quad$ T. V. +2 & (4) Falling titre in B & Duration of illness 56 days \\
\hline Nil & Mar. $/ 15$. T. V. +1 & Apr. 16. B from urine & May 4, died \\
\hline Nil & T. V. +2 & Sept. 5. Aggl. B 1 in 50 & Convalescent (Sept. 15) \\
\hline
\end{tabular}

Nil Oct./14. T. V. +2 June 30. B from stool July 7. A from blood

Duration of illness 89 days. Fever of relapse, 57th69 th days

Tender June $/ 15$. T. V. +2 Dec. 15 . T. V. +1

(4) Varying titre in T. A Duration of illness 61 days. 12 Apr. 16. T.A. B. Diagn.= Enteric group Fever of relapse, 14th$+1$

* In the column Bacteriology the left-hand numerals indicate the number of agglutinations observed. 


\section{DESCRIPTION OF PLA'IES.}

Puate 10. The stomach and duodenum from a case of spirochaetal jaundice, showing the oedematous and congested mucous membrane and the papilla.

Plate 11. A portion of the duodenum from a case of spirochaetal jaundice.

Prate 12. Naked-eye appearance of the liver in a case of spirochaetal jaundice.

Plate 13. Sections of liver from a case of spirochatal jaundice.

Plate 14. A. Section across the ampulla of Vater, showing the numerous folds, recesses, and crypts in the mucous membrane lining the ampulla. B. Enlargement of part of the section shown in $\mathrm{A}$.

Plate 15. A. Guinea-pig's liver, showing spirochaetes. B. Field showing spirochaetes and cocci in urine.

Puate 16. A. Control urine showing spirochaetes, other organisms, and crystals. B. Sections of liver from case of spirochaetal jaundice (dead in a fortnight). 


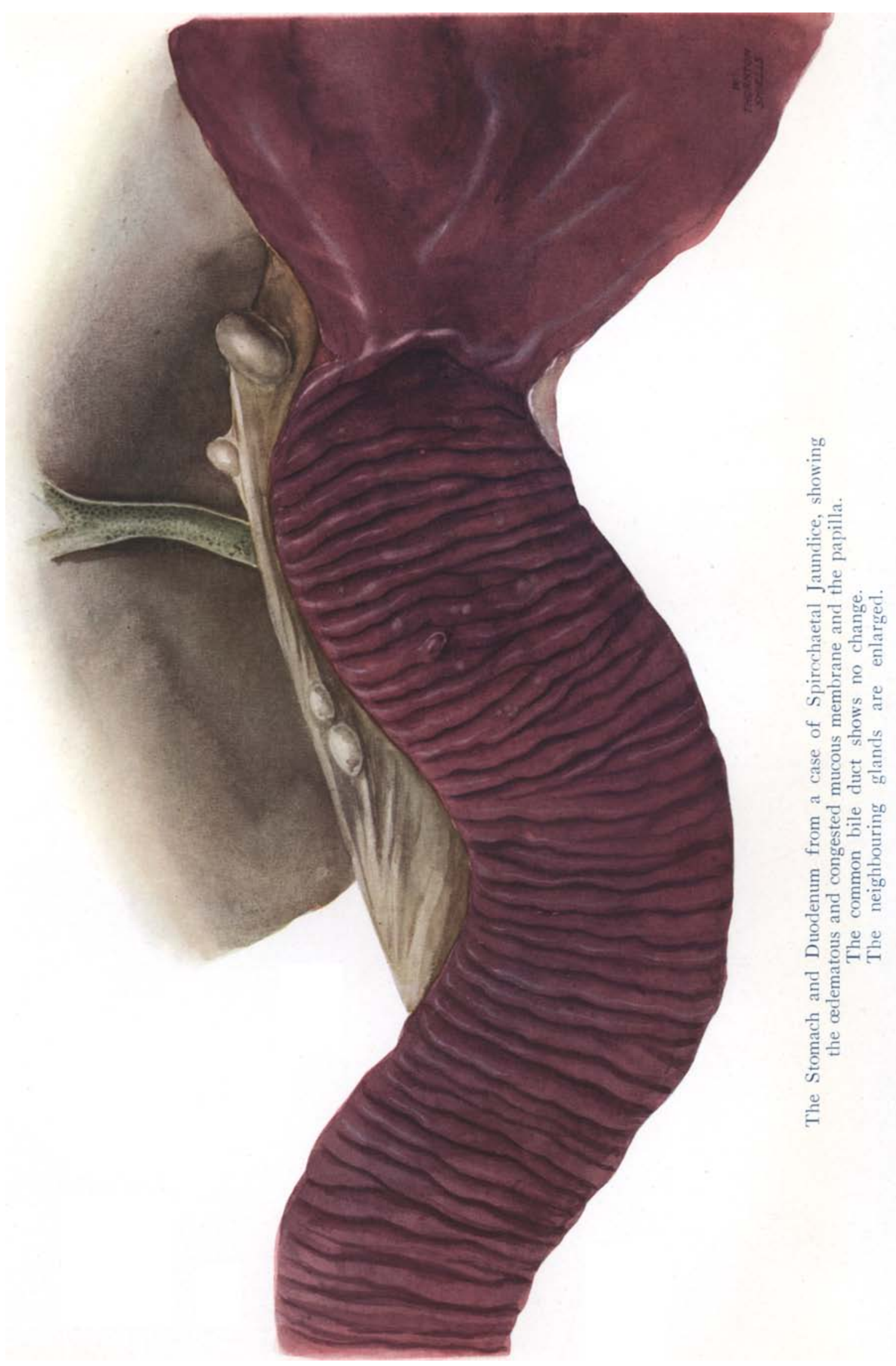




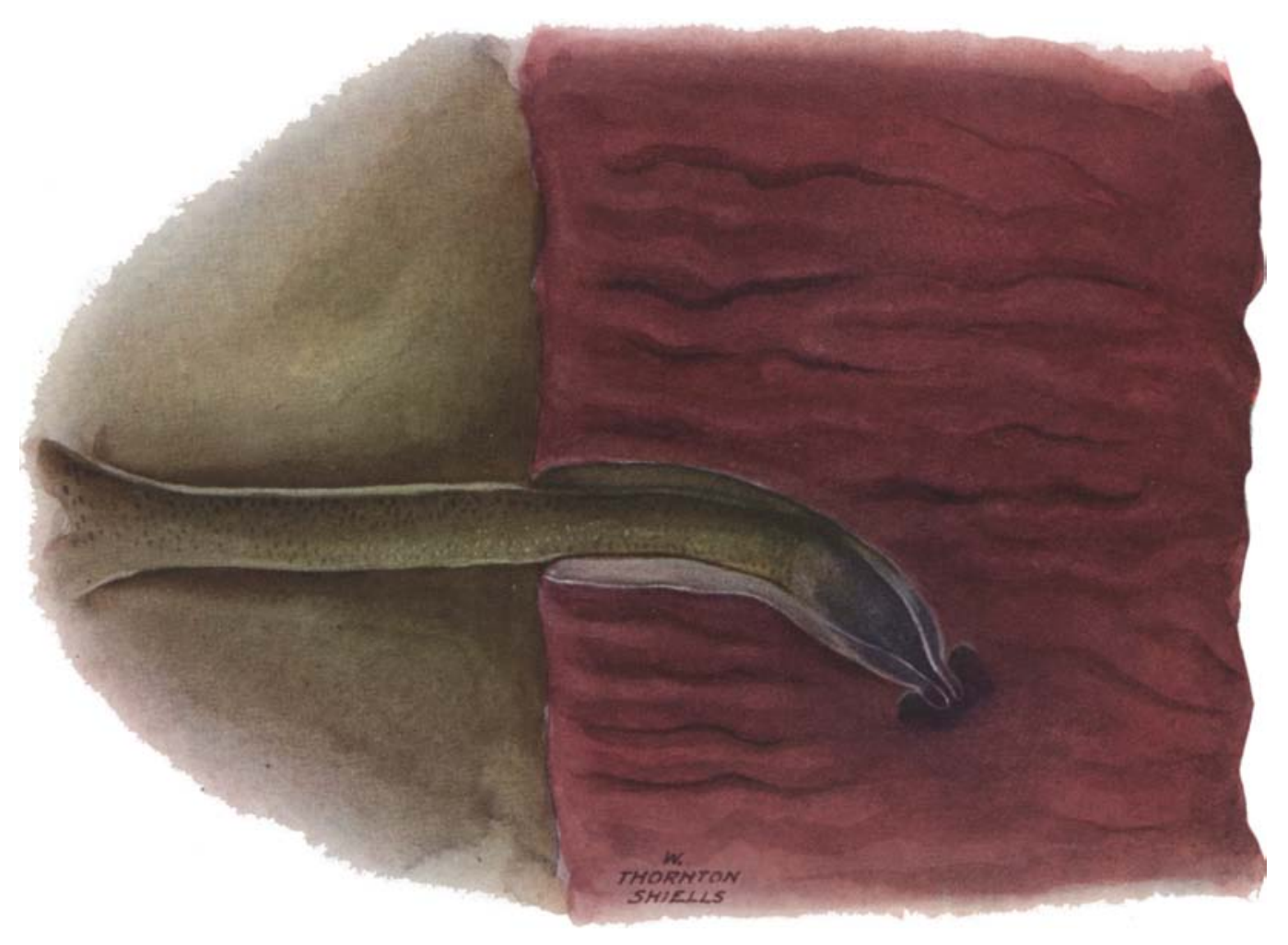

A portion of the Duodenum from a case of Spirochaetal Jaundice. The terminal portion of the bile duct is swollen and congested, especially round the papilla.

The rest of the common bile duct is normal in appearance. 


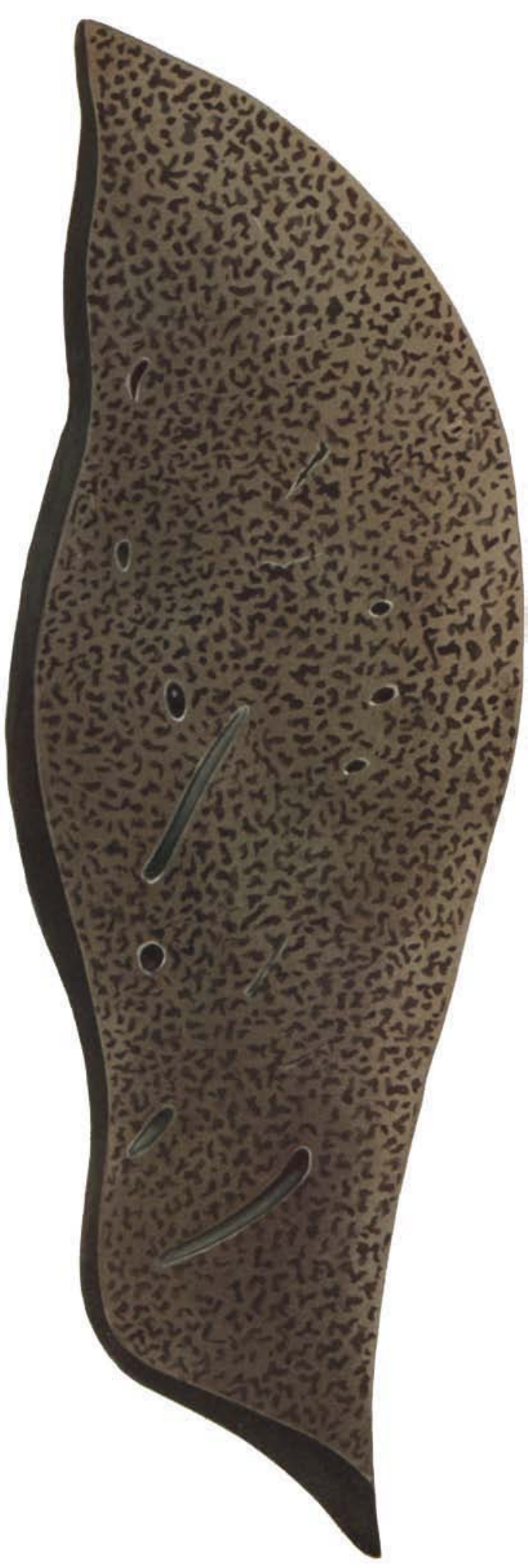

. Saketleye appearance of the Liver in a case of Spirorhaetal Jaundice. 

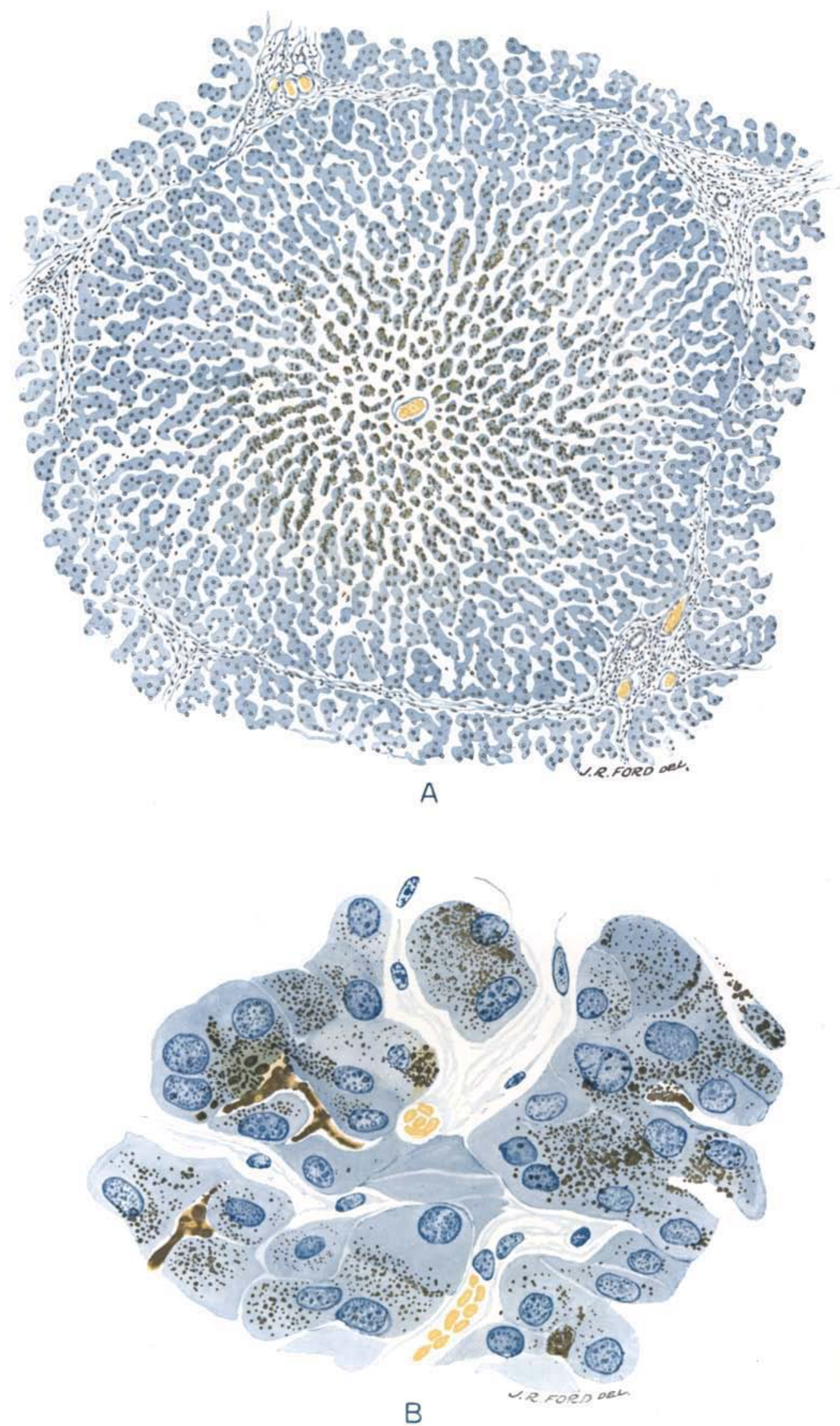

Sections of Liver from a case of Spirochaetal Jaundice. The Liver cells and their arrangement appear normal.

A shows collections of cells in portal areas.

$\mathrm{R}$ shows hiliarv stasis. 

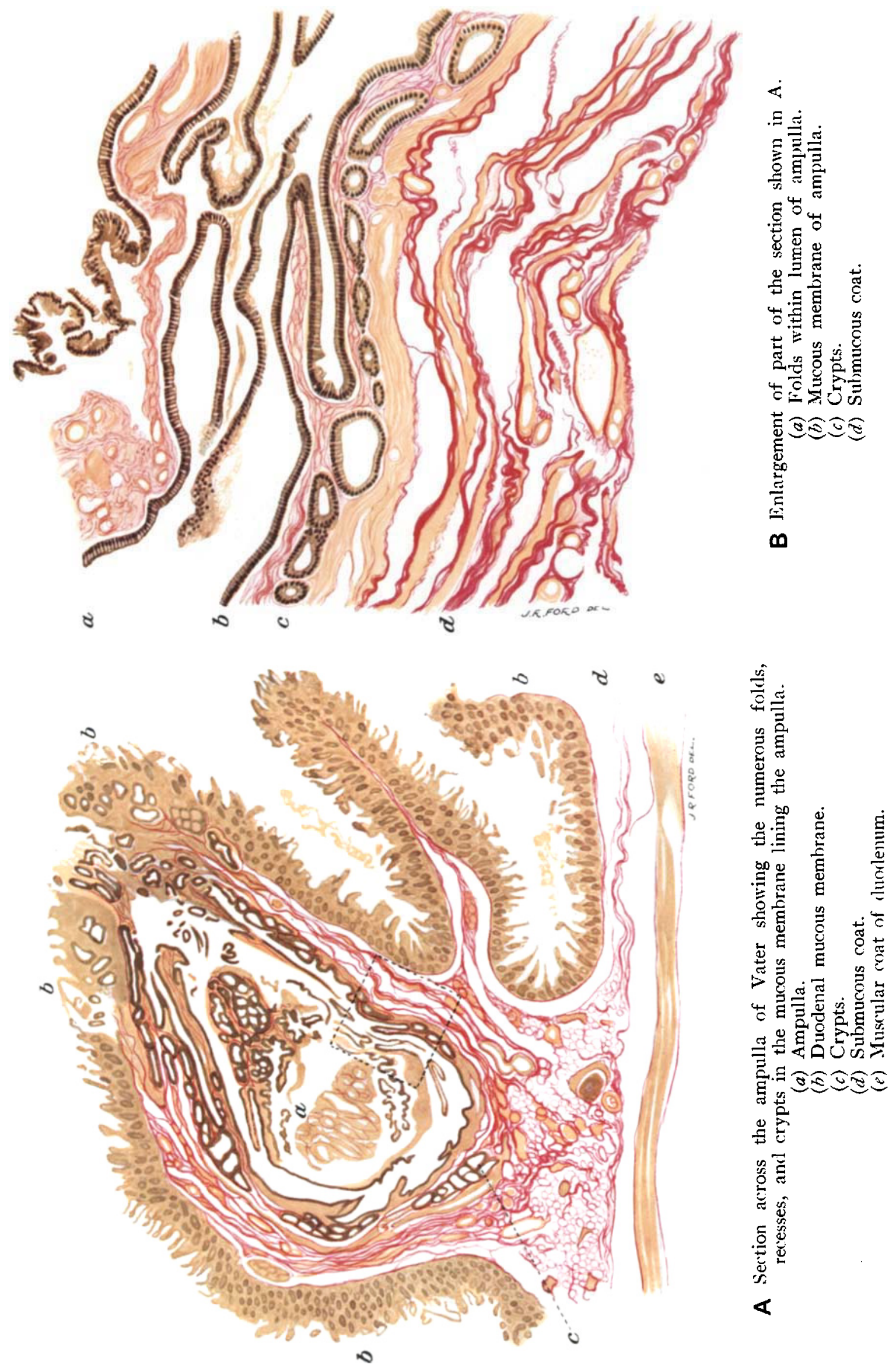


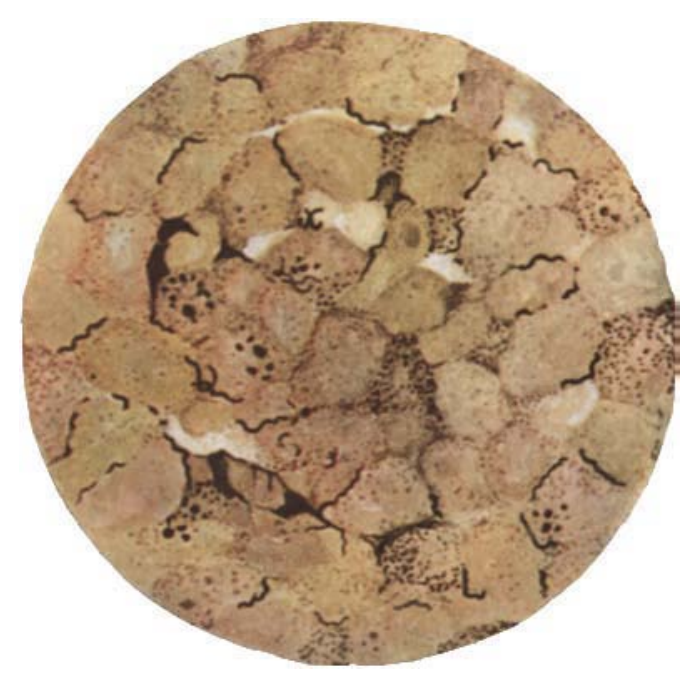

A Ciuinea-pig's Liver showing Sipirorhaetes.

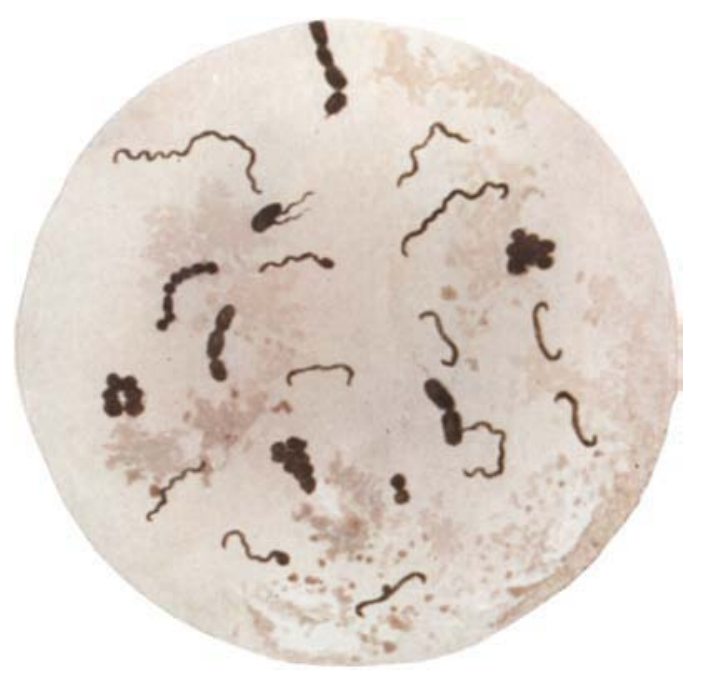

B lield showing sppirochates and cerci in urine. 


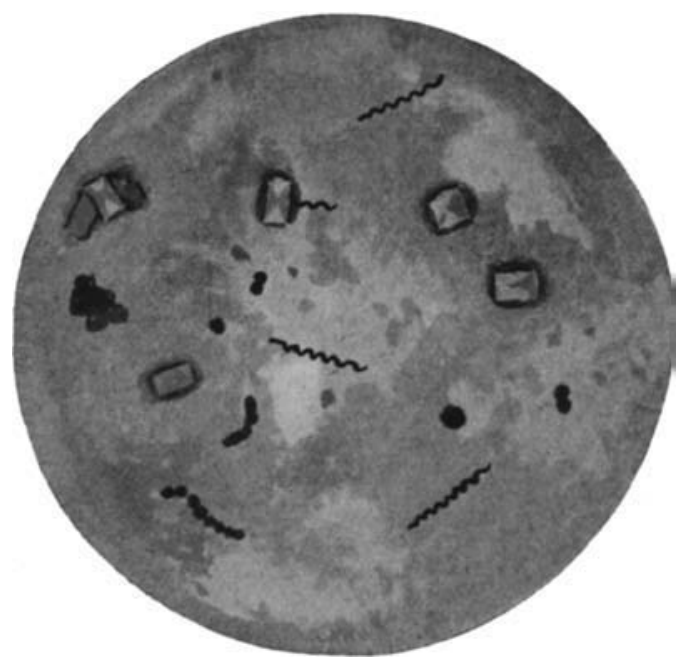

(A) Control urine showing Spirochaetes, other organisms and crystals

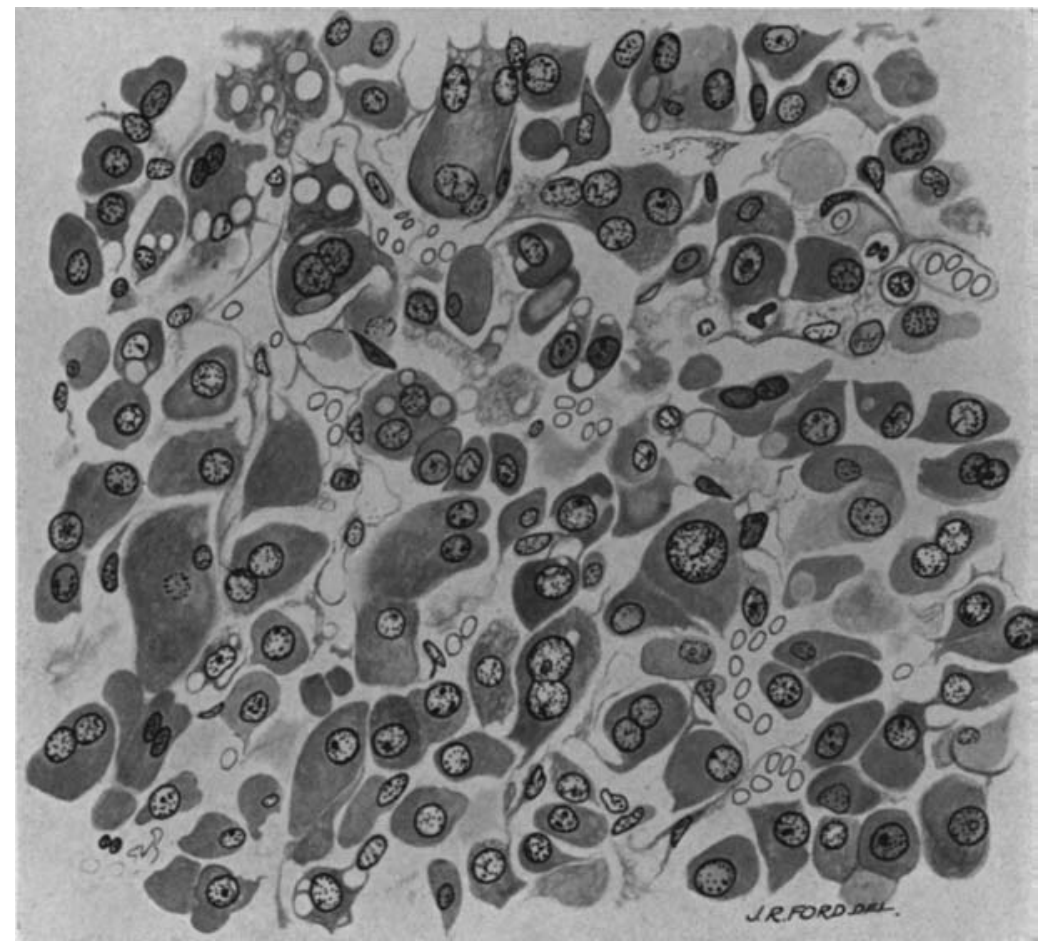

(B) Section of liver from case of spirochaetal jaundice. (Dead in a fortnight) 